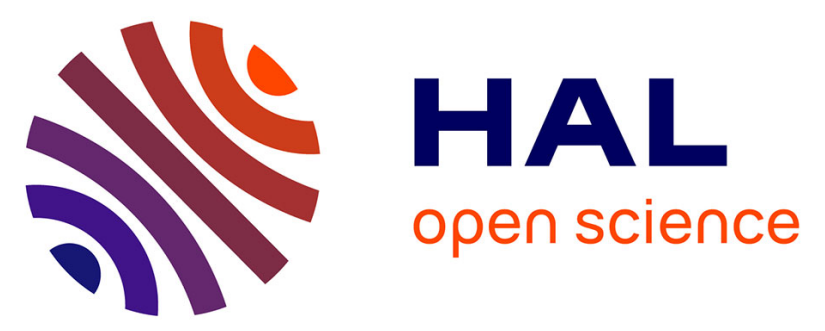

\title{
Influence of bone microstructure on the mechanical properties of skull cortical bone - A combined experimental and computational approach
}

Sourabh Boruah, Damien Subit, Glenn R Paskoff, Barry S. Shender, Jeff R. Crandall, Robert S. Salazar

\section{To cite this version:}

Sourabh Boruah, Damien Subit, Glenn R Paskoff, Barry S. Shender, Jeff R. Crandall, et al.. Influence of bone microstructure on the mechanical properties of skull cortical bone - A combined experimental and computational approach. Journal of the mechanical behavior of biomedical materials, 2017, 65, pp.688-704. 10.1016/j.jmbbm.2016.09.041 . hal-02496520

\section{HAL Id: hal-02496520 \\ https://hal.science/hal-02496520}

Submitted on 3 Mar 2020

HAL is a multi-disciplinary open access archive for the deposit and dissemination of scientific research documents, whether they are published or not. The documents may come from teaching and research institutions in France or abroad, or from public or private research centers.
L'archive ouverte pluridisciplinaire HAL, est destinée au dépôt et à la diffusion de documents scientifiques de niveau recherche, publiés ou non, émanant des établissements d'enseignement et de recherche français ou étrangers, des laboratoires publics ou privés. 


\title{
Influence of bone microstructure on the mechanical properties of skull cortical bone - A combined experimental and computational approach ${ }^{\text {ir }}$
}

\author{
Sourabh Boruah ${ }^{\mathrm{a}, *}$, Damien L. Subit ${ }^{\mathrm{a}, \mathrm{b}}$, Glenn R. Paskoff ${ }^{\mathrm{c}}$, Barry S. Shender ${ }^{\mathrm{c}}$, Jeff R. Crandall ${ }^{\mathrm{a}}$, \\ Robert S. Salzar ${ }^{a}$
}

a Center for Applied Biomechanics, University of Virginia, Charlottesville, VA, USA

b Institut de Biomécanique Humaine Georges Charpak, Ecole Nationale Superieure d'Arts et Metiers, Paris, France

${ }^{\mathrm{c}}$ Human Systems Department, Naval Air Warfare Center Aircraft Division, Patuxent River, MD, USA

Keywords:

Cranium

Calvarium

Cortical tables

Dynamic tensile tests

Microstructure

Computational biomechanics

\begin{abstract}
A B S T R A C T
The strength and compliance of the dense cortical layers of the human skull have been examined since the beginning of the 20th century with the wide range in the observed mechanical properties attributed to natural biological variance. Since this variance may be explained by the difference in structural arrangement of bone tissue, micro-computed tomography $(\mu \mathrm{CT})$ was used in conjunction with mechanical testing to study the relationship between the microstructure of human skull cortical coupons and their mechanical response.

Ninety-seven bone samples were machined from the cortical tables of the calvaria of ten fresh post mortem human surrogates and tested in dynamic tension until failure. A linear response between stress and strain was observed until close to failure, which occurred at $0.6 \%$ strain on average. The effective modulus of elasticity for the coupons was $12.01 \pm 3.28 \mathrm{GPa}$. Porosity of the test specimens, determined from $\mu \mathrm{CT}$, could explain only $51 \%$ of the variation of their effective elastic modulus. Finite element (FE) models of the tested specimens built from $\mu \mathrm{CT}$ images indicated that modeling the microstructural arrangement of the bone, in addition to the porosity, led to a marginal improvement of the coefficient of determination to 54\%. Modulus for skull cortical bone for an element size of $50 \mu \mathrm{m}$ was estimated to be $19 \mathrm{GPa}$ at an average. Unlike the load bearing bones of the body, almost half of the variance in the mechanical properties of cortical bone from the skull may be attributed to differences at the sub-osteon $(<50 \mu \mathrm{m})$ level. ANOVA tests indicated that effective failure stress and strain varied significantly between the frontal and parietal bones, while the bone phase modulus was different for the superior and inferior aspects of the calvarium. The micro FE models did not indicate any anisotropy attributable to the pores observable under $\mu \mathrm{CT}$.
\end{abstract}

\section{Introduction}

In the last decade traumatic brain injury (TBI) has emerged as a major problem in the United States military, so much so that it has been called the signature wound of war (Snell and Halter, 2010). The etiology of this injury is still unclear, however a vast majority of these cases are closed head injuries where brain damage occurs without any fracture of skull bone (Fischer, 2010). FE models of the head are already playing a big role in the research of TBI and researchers have shown that skull bending may be as important as direct transmission of compressive stress waves in the context of blast brain injury (Moss et al., 2009). The human calvarium has a sandwich structure and it exhibits stiffer bending compared to its through-the-thickness defor- mation. To accurately model both bending and through-the-thickness deformation mode, it is essential to separate the different layers of the calvarium and use correct sub-failure mechanical properties for the three layers of the calvarium.

Historically the problem of head injury has been approached by various researchers using impact experiments conducted on the whole human head or skull (Nahum et al., 1968; Hodgson et al., 1970; Got et al., 1978). Since these studies related kinematic indicators such as velocity and acceleration to head injury, a physical model of the head was required for the assessment of the risk of head injury as a result of mechanical insult. Materials for construction of this physical model were selected by studying the mechanical response of the various components of the head, including the skull. Apart from this, these 
studies provided data for development of computational models of the head which can be used to study the response of the head to any mechanical input.

The first comprehensive study of tensile and compressive failure properties of cortical bone from the skull was published in Evans and Lissner (1957). More than a decade later, the mechanical stiffness at quasi-static and dynamic rates was reported by Robbins and Wood (1969) and Wood (1971) respectively. Wood had studied 120 skull cortical bone specimens from thirty subjects at various rates of loading. Although a large sample was tested, no objective distinction of the different layers of the calvarium was done. Moreover, material inhomogeneity within the skull cortical bone samples was not addressed in any of these studies. Therefore, it is unknown to what extent the mechanical properties found in these studies are representative of the cortical layer of the human calvarium.

Properties of cortical bone have also been derived from composite skull bone bending tests (Hubbard, 1971; Delille et al., 2007; Motherway et al., 2009; Auperrin et al., 2014; Rahmoun et al., 2014). Inhomogeneity and porosity in the material used in a composite skull bending study was accounted for using a three-layer model by Hubbard (1971) and the layer thicknesses were calibrated through visual inspection. Delille et al. (2007) and Auperrin et al. (2014) have used mineral (ash) percentage to calibrate the thicknesses of hollow beam models of samples from the calvarium in their bending study. Microstructure from micro-radiology was used in conjunction with bending tests only recently by Motherway et al. (2009). However, in all these cases, curvature of the skull was ignored and a simplified straight beam model was assumed. Ultrasound transmission was used by (Peterson and Dechow, 2002) to estimate the Young's modulus of human skull cortical bone.

Pores in the human calvarium cannot be resolved using clinical computed tomography, but they can be discerned using micro computed tomography $(\mu \mathrm{CT})$. In the only studies of the mechanical properties of skull cortical bone where $\mu \mathrm{CT}$ was used (Motherway et al., 2009; Rahmoun et al., 2014), it was assumed, despite evidence to the contrary (Rho et al., 1997; Zysset et al., 1999), that the bone in the cortical layers and the cancellous diploe layer had equal modulus. It is also unknown if the mechanical properties vary with location on the skull.

There are many papers in the literature which investigate the mechanical properties of cortical bone obtained from the long bones of the human body, and several of them have analysed the effect of porosity in the microstructure (McCalden et al., 1993; Rho et al., 1993; Wang et al., 2002; Zioupos and Currey, 1998). Unlike coupons harvested from the skull, these samples are composed of continuous bone consisting of cemented osteons and they do not have pores except the haversian canal system. The structures inside the osteons have been examined under microscopy using staining techniques. Wang et al. (2002) have described the relationship of mechanical properties with mineralization and collagen cross-link density, which are nano scale phenomena. These topics are combined under bone material quality research, particularly in the context of fragility and aging. Due to the thinness of the cortical layers in the skull, it is difficult to obtain samples that do not have interstitial pores in the osteon matrix.

Arrangement of osteons in cortical bone may lend anisotropy to its macroscopic mechanical behavior, making it stiffer under deformation along the grain as compared to the transverse directions. Dempster (1967) concluded that on the surface of the skull vault, away from the forehead and internal sagittal markings, osteonal grain patterns were randomly oriented. This observation concurs with all research about the mechanical response of skull cortical bone: although osteonal bone is inherently anisotropic, because of the randomly oriented osteons, the macroscopic mechanical response of the cortical layers of the skull may be considered to be transversely isotropic about the axis perpendicular to the surface.

Finite element (FE) models of the head typically use a single isotropic material for the entire skull thickness. These models cannot simultaneously exhibit the stiffened bending response and softer through-the-thickness deformation response that is characteristic of the skull sandwich structure. Models that do include multiple materials (Horgan and Gilchrist, 2003; Panzer et al., 2012; Asgharpour et al., 2014) use a fixed ratio of thicknesses of the three layers of the skull using material properties taken from mechanical testing of cortical tensile coupons. Because of the lack of objective delineation of the three layers of the calvarium, it is not certain if the material properties used for the different layers actually represent the material in those layers. In a bid to match the bending response, these models exhibit increased stiffness under through-the-thickness deformation (Boruah et al., 2013).

The objective of this study was to examine the Young's modulus of cortical bone from the skull, specifically the calvarium, at a sub-osteon element size $(50 \mu \mathrm{m})$, under the assumption that the bone behaves in an isotropic fashion at this length scale. Despite this assumption, at the macroscopic scale, the porous bone samples may behave in an anisotropic fashion depending on the existence of any directionality in the bone scaffold. A three-step approach was designed. First, tensile coupons were harvested from the outer cortical layer of the calvarium and imaged using $\mu \mathrm{CT}$ to analyze the bone micro-structure. Second, the coupons were tested under dynamic tension. Third, coupon specific FE models were developed to account for the micro-structural arrangement of osteons and to identify the mechanical properties of bone at a microscopic scale. Explosive blast events associated with conventional explosive devices typically last a few milliseconds (Moss et al., 2009; Panzer et al., 2012). The rate of tensile loading of the coupons was chosen to represent quasi-static rates compared to blast rates. The properties found using this approach will be suitable for application to a head FE model which uses layer thicknesses of the calvarium that were determined using $\mu \mathrm{CT}$ (Boruah et al., 2015).

In addition to the assessment of influence of microstructure on the mechanical properties of the cortical layers of the calvarium, the statistical difference in these properties between subjects and between the frontal and parietal bones and between the superior and inferior aspects of the calvarium within subjects was also determined.

\section{Materials and methods}

Cortical coupon samples were obtained from the outer cortical tables of ten adult male post-mortem human surrogates (PMHS), with an upper age limit of 70 years (Table 1). All test subjects were frozen post-mortem and thawed for use. Torimitsu et al. (2014) found that freezing-thawing cycles have no significant effect on the mechanical properties of bone. All subjects were screened for hepatitis A, B, C, and HIV and for pre-existing pathology that may influence bone properties, such as trauma and metastatic or wasting diseases. Pre-test radiographs were analyzed to verify that specimens with existing bone conditions, such as osteoporosis or osteopenia, on the basis of bone mineral density at the lumbar vertebrae and the femoral head

Table 1

Anthropometry of test subjects.

\begin{tabular}{llll}
\hline Subject no. & Age & Height $[\mathrm{cm}]$ & Weight $[\mathrm{kg}]$ \\
\hline 1 & 58 & 188 & 104 \\
2 & 41 & 180 & 71 \\
3 & 49 & 175 & 57 \\
4 & 51 & 173 & 91 \\
5 & 66 & 178 & 70 \\
6 & 59 & 173 & 68 \\
7 & 61 & 175 & 104 \\
8 & 45 & 191 & 73 \\
9 & 49 & 175 & 77 \\
10 & 70 & 173 & \\
\hline
\end{tabular}




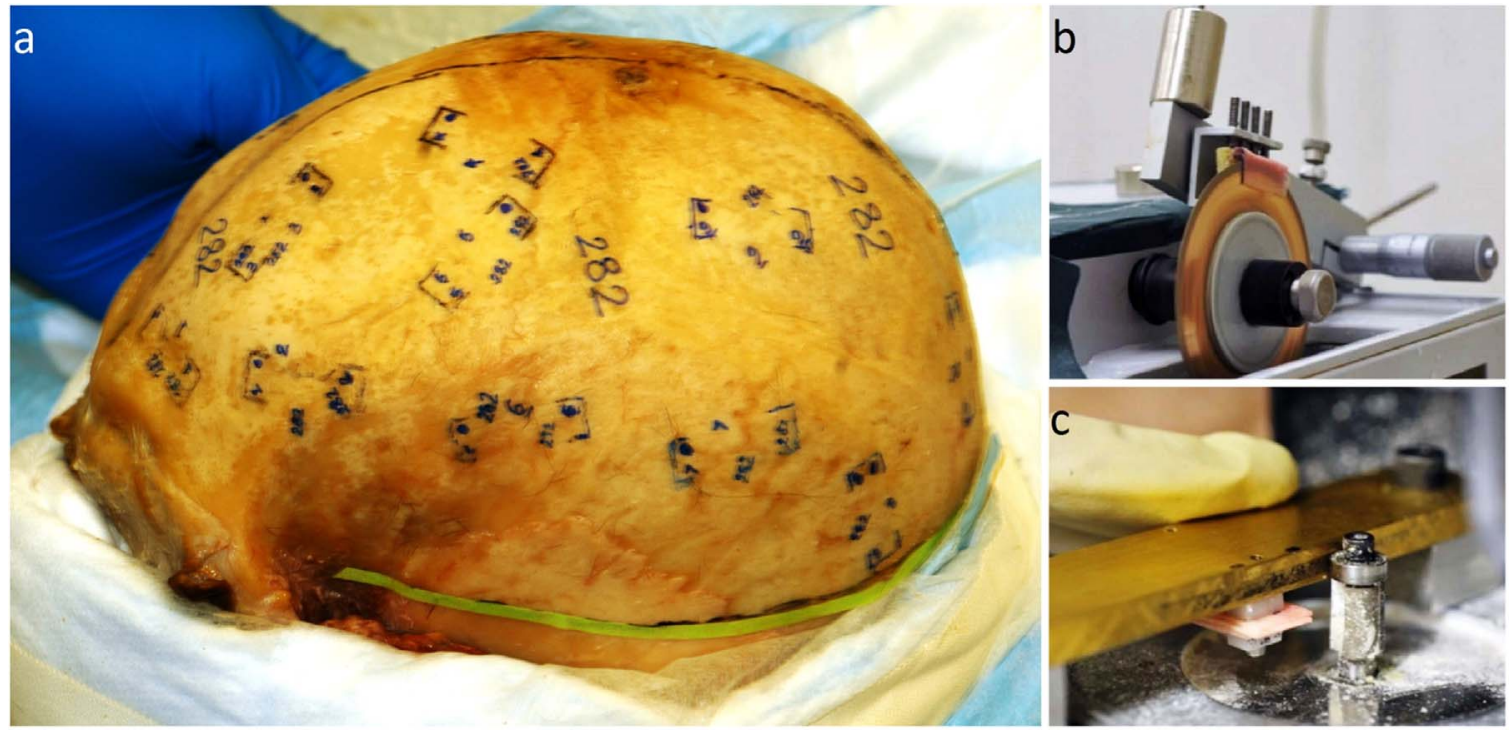

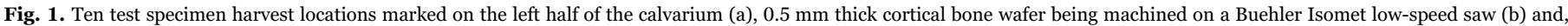
cortical bone wafers being milled (c).
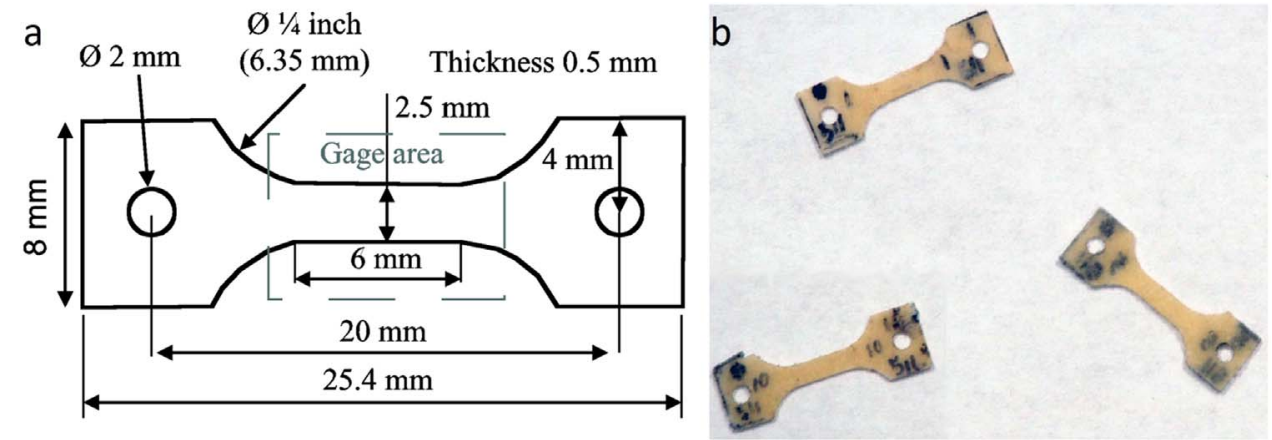

Fig. 2. Dimensions of a coupon sample (a) and A few finished coupons (b).
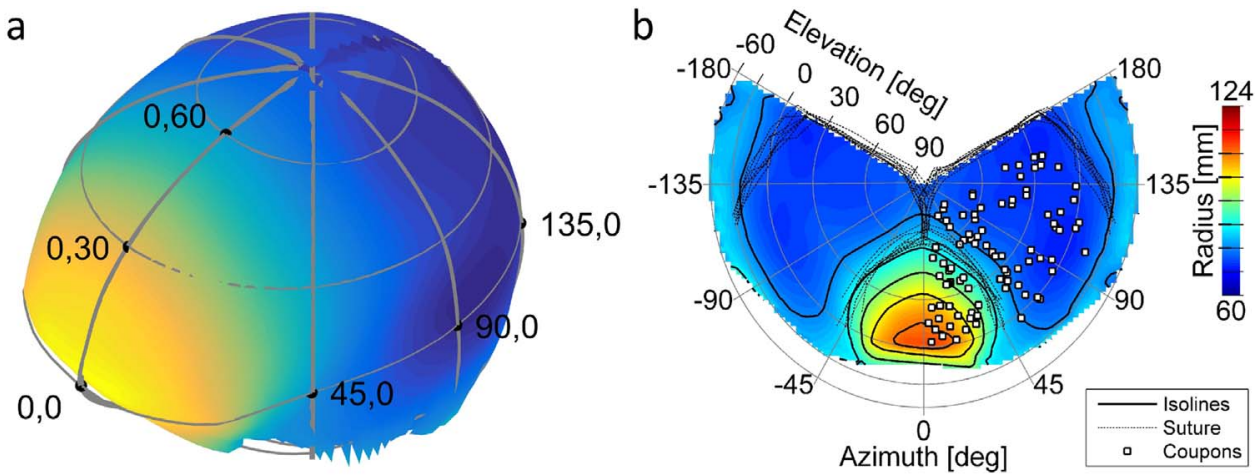

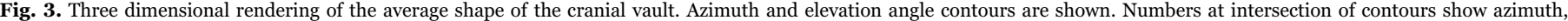

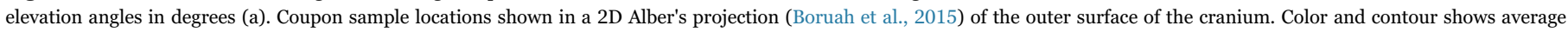

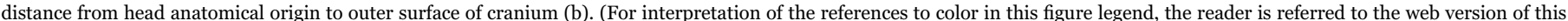
article.)

(measured using dual-energy X-ray absorptiometry), were excluded from the study. All test procedures were approved by the University of Virginia Institutional Review Board for Human Surrogate Use. Clinical CT was performed on all subjects at an in-plane resolution of $0.980 \mathrm{~mm} /$ voxel, and a slice thickness of $0.625 \mathrm{~mm}$ in order to identify potential locations of harvesting specimens.

Ten locations with relatively less curvature were identified on the left half of the calvarium. These locations varied slightly from skull to skull, if needed, to avoid unsuitable anomalies and the sutures. Bone samples were harvested from the outer cortical layer at these locations.
Following thawing of the head and removal of the scalp, these ten locations were marked on the skull surface (Fig. 1a). Multiple samples were harvested from each location on the skull. These were either from the same depth and adjacent to each other, or from different depths on top of each other. The actual positions of the harvest locations were measured and recorded for each skull relative to an anatomical landmark based head coordinate system. The origin of the head coordinate system was at the centroid of the nasion, bregma, lambda and the two porions. The horizontal plane was parallel to the Frankfort plane and $n \pi$ ( $n$ is any integer) azimuth corresponded to a plane 


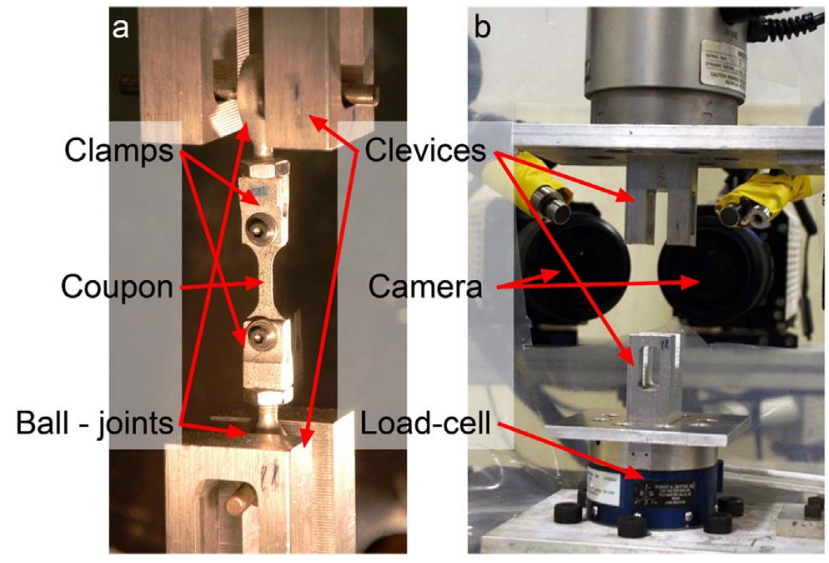

Fig. 4. Self aligning coupon testing jig mounted on clevises of the 8874 servo-hydraulic system (a). Tensile test setup showing the camera arrangement for the ARAMIS-3D system (b).

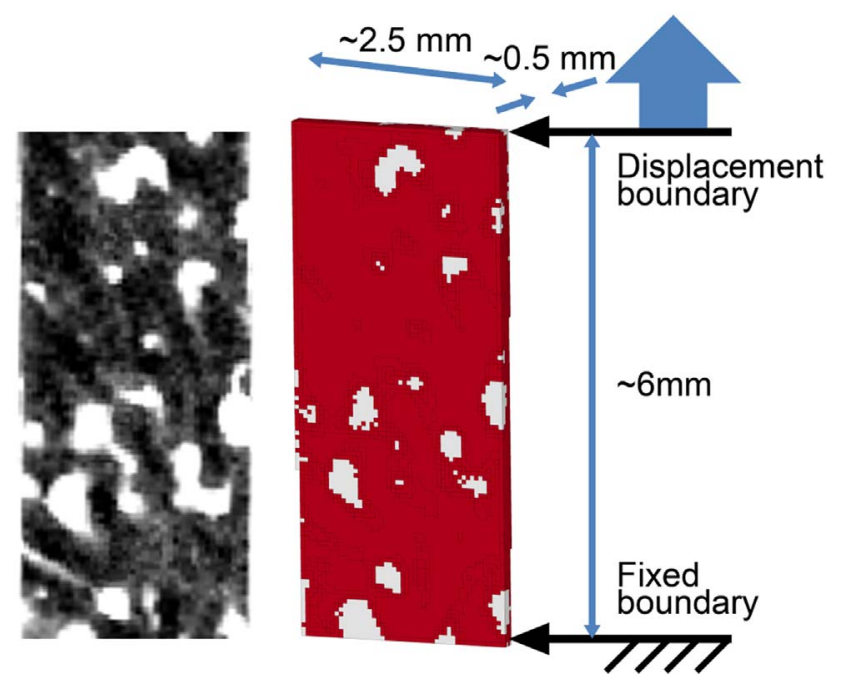

Fig. 5. Micro CT slice of a coupon gage area (left; color indicates bone probability: white -0 , black -1 ) and corresponding FE mesh (right).

Table 2

Simulation matrix.

\begin{tabular}{lll}
\hline Number of coupons & Strain [\%] & Modulus [GPa] \\
\hline $\begin{array}{l}\text { Preliminary } \\
5\end{array}$ & $0.05,0.1,0.5,2.0$ & 16.00 \\
5 & 0.1 & $12.00,15.00,18.00,21.00$ \\
Final & & \\
97 & 0.1 & $12.00,21.00$, sample dependent value \\
\hline
\end{tabular}

perpendicular to the line joining the two porions (Boruah et al., 2015). The calvarium was then removed using a circular oscillating saw and split into the right and left halves. The left calvarium was first cut into smaller segments using a band saw. These segments were machined under distilled water irrigation into $0.5 \mathrm{~mm}$ thick cortical bone wafers using an Isomet low-speed diamond wafering saw (Buehler, Lake Bluff, Illinois), which was equipped with a screw gauge (Fig. 1b). The cortical wafers thus obtained from the calvarium were mounted on a router and the final shape was milled (Fig. 1c). The thickness of the coupon was precisely ground to $0.5 \mathrm{~mm}$ using a custom sanding block. The dimensions of the finished coupons were based on previous work by (Subit et al., 2011, 2013) to allow the creation of test samples mostly composed of cortical bone (Fig. 2). The harvested coupons were then stored submerged in saline solution inside polypropylene tubes at $5.5^{\circ} \mathrm{C}$. A total of 115 coupons were harvested. The locations from which the samples were harvested have been shown in Fig. 3 in terms of azimuth and elevation angles. The coupons were scanned using a VIVACT40 $\mu \mathrm{CT}$ machine (isotropic resolution $-25 \mu \mathrm{m}$; Scanco, Brüttisellen, Switzerland).

After completion of $\mu \mathrm{CT}$ imaging, the coupons were tested to failure with the tensile test setup described in Subit et al. (2011). It consisted of a custom built test fixture attached to the 8874 servo-hydraulic system (Instron, Norwood, Massachusetts). The test fixture, consisting of two clamps and ball joints, was designed to self-align in the direction of load (Fig. 4a). The lightweight clamps have a $0.5 \mathrm{~mm}$ wide slot for insertion of the coupons and a $2 \mathrm{~mm}$ screw to apply the clamping force. Ball joints accommodated the roller pins which attached the clamps to the clevises on the driving machine. The top clevis was attached to the hydraulic actuator and the bottom was attached to the stationary loadcell (Honeywell model 41). The roller-clevis joint constrained only vertical motion, allowing the coupon-clamp system to self-align to the vertical axis upon application of pre-load. A digital image correlation system was used to measure displacement and strain (Aramis v6.2, GOM mbH, Braunschweig, Germany). The entire setup is shown in Fig. 4b. Two high speed cameras (NAC GX-1, NAC Image Technology, Tokyo, Japan) recorded images at $5000 \mathrm{fps}$, using a $105 \mathrm{~mm}$ macro lens (NIKON AF-S VR Micro-Nikkor). These images were used to measure strain and displacement. The load-cell data was acquired at $100 \mathrm{kHz}$ using a DEWE-2010 data acquisition system (Dewetron, Graz, Austria). The tensile tests were conducted after application of a preload of $\sim 5 \mathrm{~N}$. The Instron actuator was driven at a speed of $24 \mathrm{~mm} / \mathrm{s}$ (target strain rate $400 \% / \mathrm{s}$ ). All data was filtered using a low-pass butterworth filter with a cut-off frequency of $2 \mathrm{kHz}$.

Before tests were conducted, a black and white speckle pattern (speckle size $\sim 0.1 \mathrm{~mm}$ ) was applied on the coupon surfaces. The software defines square facets several pixels across on the reference image, and tracks the speckle pattern within each facet to calculate displacements. The cameras remained stationary. The software is capable of assessment of out-of-plane motion using a pair of cameras calibrated for a test volume, yielding a full 3D displacement field of the surface under observation. In order to ascertain that there was no significant out-of-plane motion leading to incorrect 2D displacement field estimation, some tests were carried out with a calibrated pair of cameras looking at one surface of the coupon (such a setup is seen in Fig. 4b). Once it was confirmed that out-of-plane displacements were negligible, the remaining tests were conducted with the two cameras on opposite sides of the coupon, each looking at the inner and outer surfaces. Coupon surface displacement fields from image analysis were used to generate strain fields on the coupon surfaces. For finding effective mechanical properties at the length scale of the coupons, average vertical strain in the gage area was used in the analysis. Engineering stress was calculated by dividing force by the coupon gage cross-sectional area. Coupon gage cross-sectional area was the average area of the rectangular bounding box of the coupon gage area on a slice-by-slice basis calculated from $\mu \mathrm{CT}$.

Coupons of pure cortical bone could not be obtained from the calvarium because of its curvature combined with the slenderness of the cortical layer (thickness $\sim 0.5 \mathrm{~mm}$ ), and they invariably contained pores. The elastic modulus of the bone material was identified using an inverse FE method. Micro CT images of the coupons were segmented using a probabilistic segmentation method described in Boruah et al. (2015). In summary, the distribution of apparent density within the volume of each sample was analyzed to determine a probability function which estimates the probability of any voxel belonging to the bone phase on the basis of its apparent density. The coupons were segmented using a random number generator that was biased using this probability function in conjunction with apparent density from $\mu \mathrm{CT}$. The bone volume fraction (BVF) of the gage area of each coupon was computed from the ratio of number of voxels belonging to bone to the number of total voxels in the coupon gage area (resolution of 

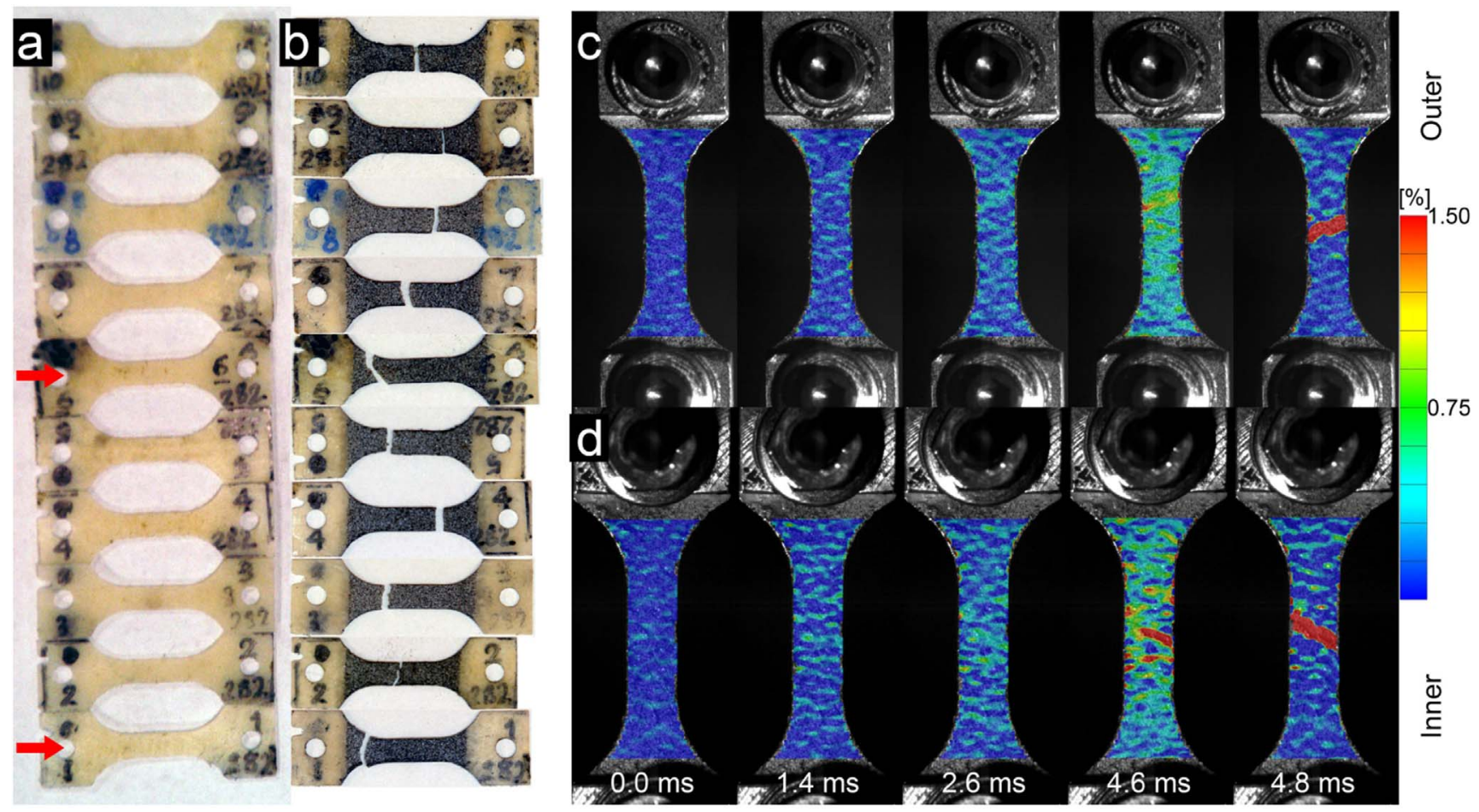

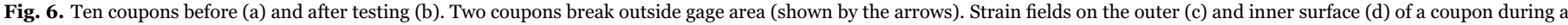

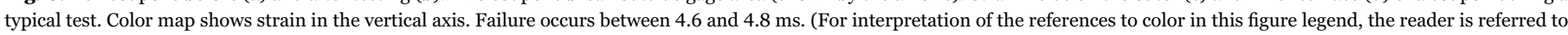
the web version of this article.)
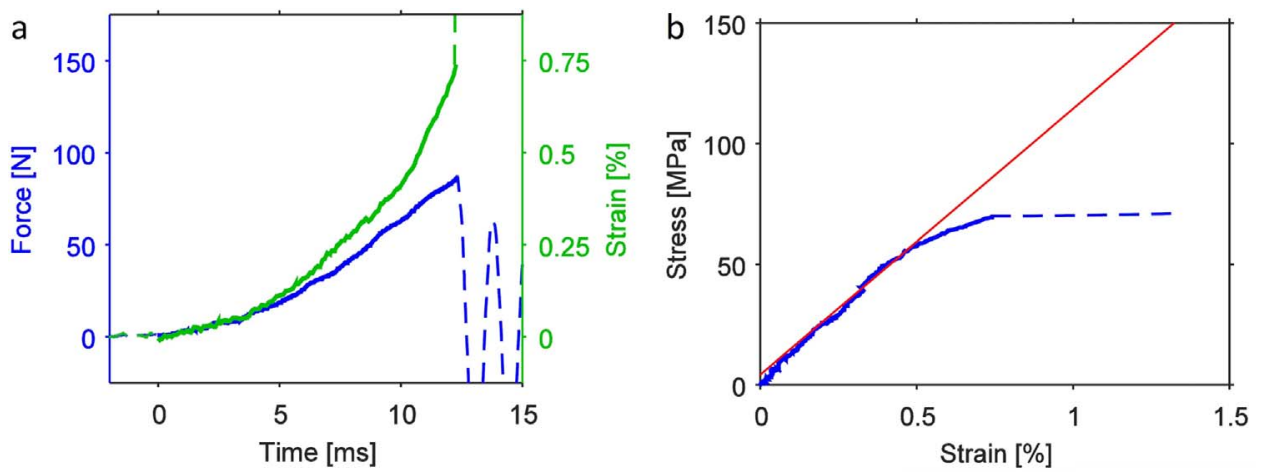

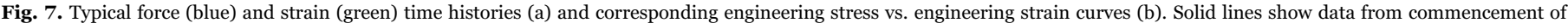
loading to time of failure. (For interpretation of the references to color in this figure legend, the reader is referred to the web version of this article.)

$25 \mu \mathrm{m})$. This metric was used as a quantitative descriptor of the bone microstructure for looking at correlations with mechanical properties.

The meshes for the micro FE models of the gage area of each coupon were constructed at reduced resolution $(50 \mu \mathrm{m}$ element size; Fig. 5) because full resolution ( $25 \mu \mathrm{m})$ meshes were computationally prohibitive. A mesh convergence study was not done. There were typically 50,000 cubical elements representing bone in the coupon gage area. It was assumed that the pores had no contribution to the tensile response and they were not meshed.

LS DYNA (R7.1.1, LSTC, Livermore, CA) implicit was used to solve the FE models to compute the structural stiffness of the coupons as a function of the elastic modulus of the bone phase. The nodes in the bottom of the gage area were constrained in the vertical axis, but were free to move along the transverse axes. The nodes at top were displaced along the vertical axis corresponding to $0.1 \%$ strain. They were also free in the transverse axes (Fig. 5). This arrangement allowed only force in the vertical axis and moments in the transverse axes at the top and bottom boundaries.
The bone elements were cubic constant stress solid elements. Their constitutive behavior was defined as isotropic linear elastic using the LS DYNA MAT_ELASTIC card. The Young's modulus of bone elements in each coupon was optimized to match the experimental force response. This modulus is referred to as the bone phase modulus in this article. The effect of microstructural arrangement of bone, at a length scale of greater than $50 \mu \mathrm{m}$, was cancelled from the structural response of the coupon in this manner.

The determination of coupon specific Young's modulus through parameter identification was computationally intensive. To increase the tractability of the computational work, a sensitivity analysis of the simulation results to the simulation inputs was performed on a subset of five coupons. The FE models of these coupons were loaded to four different strains using a bone phase modulus of $16 \mathrm{GPa}$. The force response was perfectly linear with respect to strain in all five cases. Similarly, simulations were run for five coupons using four different bone phase moduli to a strain of $0.1 \%$. The force response was again perfectly linear. On the basis of these observations, all optimization 
Table 3

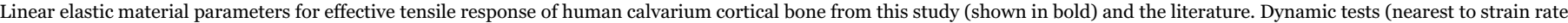
$1 \mathrm{~s}^{-1}$ ) are shown in italics. Values derived indirectly from bending tests $\left(^{*}\right)$ and ultrasound tests ( ${ }^{\dagger}$ ) are also shown.

\begin{tabular}{|c|c|c|c|c|c|c|}
\hline & \multicolumn{5}{|c|}{ Percentiles } & \multirow[t]{2}{*}{ Average \pm SD } \\
\hline & Min & 25 th & 50th & 75th & $\operatorname{Max}$ & \\
\hline \multicolumn{7}{|l|}{ Elastic modulus [GPa] } \\
\hline Current study (n=97) & 5.40 & 9.90 & 11.88 & 14.45 & 20.55 & $12.01 \pm 3.28$ \\
\hline Robbins and Wood, $1969(\mathrm{n}=50)$ & & & & & & 14.55 \\
\hline Wood, $1971(n=123)$ & & & & & & 16.00 \\
\hline Hubbard, $1971(\mathrm{n}=8)^{*}$ & 7.79 & & & & 15.31 & 9.72 \\
\hline Delille et al., $2007(n=380)^{*}$ & 2.03 & & & & 13.98 & 5.21 \\
\hline Motherway et al., $2009(n=18)^{*}$ & & & & & & $7.46 \pm 5.39$ \\
\hline Auperrin et al., $2014(n=167)^{*}$ & & & & & & $5.00 \pm 3.12$ \\
\hline Peterson and Dechow, $2002(n=140) \dagger$ & & & & & & $21.00 \pm 3.8$ \\
\hline \multicolumn{7}{|l|}{ Failure stress [MPa] } \\
\hline Current study $(n=74)$ & 20.35 & 52.12 & 63.18 & 78.08 & 124.60 & $64.95 \pm 21.08$ \\
\hline Evans and Lissner, $1957(\mathrm{n}=15)$ & 41.6 & & & & 108.9 & 70.5 \\
\hline Robbins and Wood, $1969(\mathrm{n}=50)$ & & & & & & 65.5 \\
\hline Motherway et al., $2009(n=18)^{*}$ & & & & & & $85.1 \pm 23.6$ \\
\hline \multicolumn{7}{|l|}{ Failure strain [\%] } \\
\hline Current study $(n=74)$ & 0.34 & 0.48 & 0.58 & 0.65 & 1.09 & $0.59 \pm 0.15$ \\
\hline
\end{tabular}

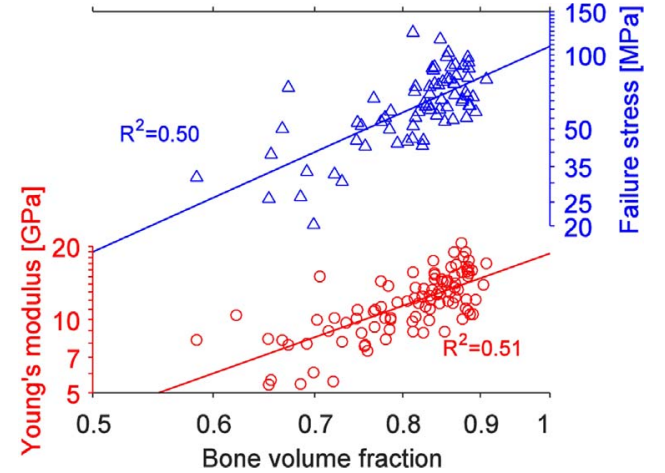

Fig. 8. Effective Young's modulus and failure stress of calvarium cortical coupons as it varies with coupon bone volume fraction. Both $\mathrm{x}$ and $\mathrm{y}$ axes are on logarithmic scales.

simulations were run to a strain of $0.1 \%$ using two seed values of bone phase moduli: 12.00 and $21.00 \mathrm{GPa}$. The optimum bone phase modulus for each coupon was then obtained through linear interpolation. A third simulation was run using this optimal bone phase modulus to confirm if it yielded the experimentally observed force

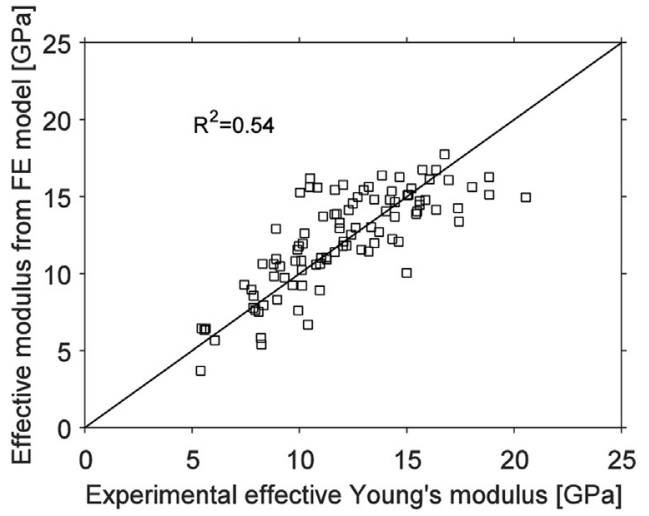

Fig. 9. Effective composite Young's modulus as predicted from implicit FE models constructed from micro CT images vs. experimentally measured effective composite Young's modulus. A constant bone phase Young's modulus of $18.51 \mathrm{GPa}$ was used. This was the optimal value determined using a least-squares approach.

(Simulation matrix Table 2). The force response was insensitive to the Poisson's ratio and a value of 0.40 was used ((Dong and Guo, 2004), (Robbins and Wood, 1969)).

Table 4

Elastic modulus for bone phase at the length scale of osteons (in GPa).

\begin{tabular}{|c|c|c|c|c|c|c|}
\hline & \multicolumn{5}{|c|}{ Percentile } & \multirow[t]{2}{*}{ Average \pm SD } \\
\hline & Min & 25th & 50th & 75th & $\operatorname{Max}$ & \\
\hline Current study $(\mathrm{n}=97)$ & \multicolumn{6}{|c|}{ Human calvarium outer cortical layer (10 subjects) } \\
\hline Power law model & 11.52 & 16.27 & 19.04 & 20.96 & 32.48 & $19.00 \pm 3.91$ \\
\hline Constant modulus FE model & 12.04 & 15.94 & 18.39 & 20.02 & 28.95 & $18.51 \pm 3.46$ \\
\hline Ascenzi and Bonucci, 1967 & \multicolumn{6}{|c|}{ Human femoral shaft osteons (3 subjects) } \\
\hline Tensile test; dry $(\mathrm{n}=7)$ & & & & & & $23.4 \pm 7.0$ \\
\hline Tensile test; wet $(\mathrm{n}=12)$ & & & & & & $11.7 \pm 5.8$ \\
\hline Rho et al., 1997 (n=12) & \multicolumn{6}{|c|}{ Human tibial cortex osteons (2 subjects) } \\
\hline Nano-indentation & & & & & & $22.5 \pm 1.3$ \\
\hline Rho et al., 1997 (n=6) & \multicolumn{6}{|c|}{ Human tibial cortex interstitial lamellae (2 subjects) } \\
\hline Nano-indentation & & & & & & $25.8 \pm 0.7$ \\
\hline Zysset et al., $1999(\mathrm{n}=1400)$ & \multicolumn{6}{|c|}{ Human (8 subjects) } \\
\hline Nano-indentation & \multicolumn{5}{|c|}{ Femoral neck; osteonal } & $15.8 \pm 5.3$ \\
\hline Nano-indentation & \multicolumn{5}{|c|}{ Femoral neck; interstitial } & $17.5 \pm 5.3$ \\
\hline Nano-indentation & \multicolumn{5}{|c|}{ Femoral neck; trabecular } & $11.4 \pm 5.6$ \\
\hline Nano-indentation & \multicolumn{5}{|c|}{ Femoral diaphysis; osteonal } & $19.1 \pm 5.4$ \\
\hline Nano-indentation & \multicolumn{5}{|c|}{ Femoral diaphysis; interstitial } & $21.2 \pm 5.3$ \\
\hline
\end{tabular}



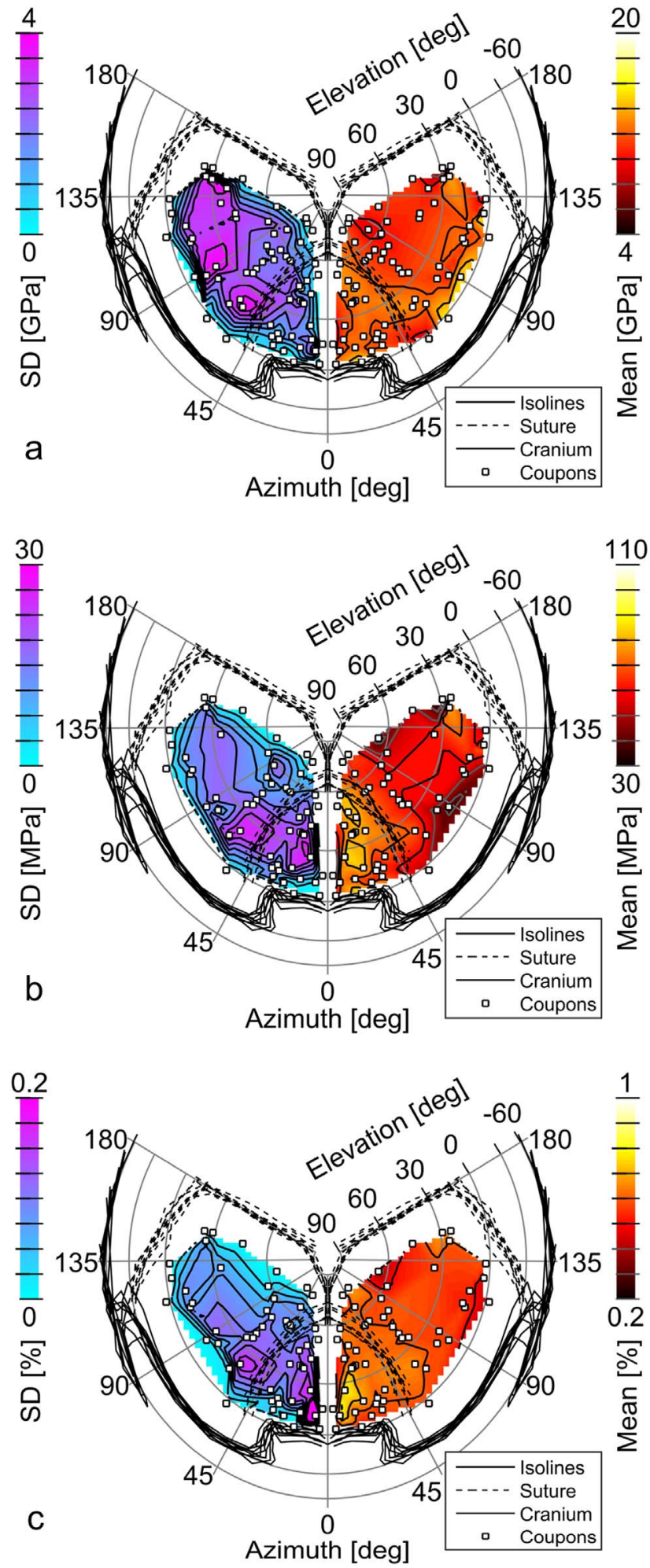

Fig. 10. Two dimensional projection of the outer surface of cranium showing variation of effective Young's modulus (a), failure stress (b) and failure strain (c) of the outer cortical layer under tension in the tangential direction. Color map on right shows mean values across different subjects and on the left shows the standard deviations. Please refer to Fig. 3a for orientation. (For interpretation of the references to color in this figure legend, the reader is referred to the web version of this article.)

\section{Results}

The results for 97 successfully tested calvarium coupon samples are presented here. Eighteen coupons were damaged during mounting on the test setup.
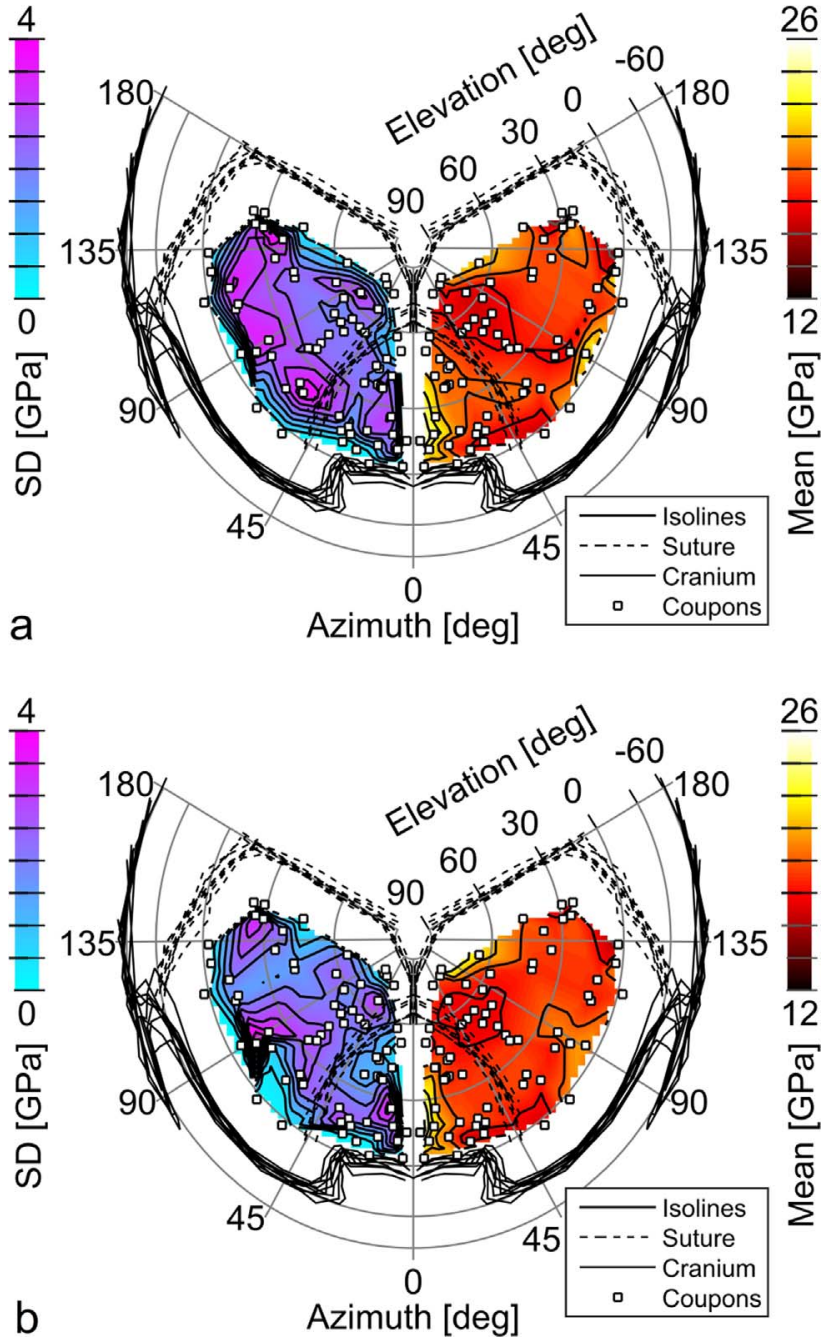

Fig. 11. Two dimensional projection of the outer surface of cranium showing variation of Young's modulus of calvarium cortical bone, derived using empirical power law (a) and implicit FE models (b). Please refer to Fig. 3a for orientation. (For interpretation of the references to color in this figure legend, the reader is referred to the web version of this article.)

Table 5

Significance of differences (p-values from ANOVA analysis) of measured and deduced properties with location on the skull. Significant differences $(\alpha=0.05)$ are shown in bold and marked by an asterisk $(*)$.

\begin{tabular}{lll}
\hline $\begin{array}{l}\text { Main effect } \\
\text { Random effect }\end{array}$ & $\begin{array}{l}\text { Frontal vs. parietal } \\
\text { Subject }\end{array}$ & $\begin{array}{l}\text { Superior vs. inferior } \\
\text { Subject }\end{array}$ \\
\hline BVF & 0.471 & 0.716 \\
Effective modulus & 0.340 & 0.483 \\
Effective failure stress & $\mathbf{0 . 0 1 9}^{*}$ & 0.760 \\
Effective failure strain & $\mathbf{0 . 0 2 4}^{*}$ & 0.513 \\
Bone phase modulus (power law) & 0.050 & 0.247 \\
Bone phase modulus (FE) & 0.196 & $\mathbf{0 . 0 2 4}^{*}$ \\
\hline
\end{tabular}

A few coupons before and after testing are shown in Fig. $6 \mathrm{a}$ and b. The strain field was measured on both coupon surfaces (Fig. 6c and d). Typically engineering stress varied linearly with engineering strain (Fig. 7), and the effective linear elastic modulus of the coupon was estimated from linear regression of stress vs. strain data within $20 \%$ to $80 \%$ of the failure strain. Non-linearity at the extreme ends of stress and strain was discounted in this manner. This range of data represents time history of approximately $10 \mathrm{~ms}$ which far exceeds conventional explosive blast event durations, and thus the modulus obtained may be treated as quasi-static relative to blast rates. Ratio of stress to strain 
deviated more than $10 \%$ from the effective modulus in half of the tests near the failure point. In 23 out of 97 successful tests, the coupons failed outside the gage area. In these cases the maximum stress and strain that were attained in the gage area were less than the failure stress and strain, because failure did not occur in the gage area, and these values were discarded in the statistical analysis of failure properties. However, the sub-failure stress vs. strain relationship is still valid for the gage area and effective elastic modulus can be derived. The stress vs. strain curves are not perfectly linear, even within the 20 to $80 \%$ domain, and the numbers reported here may not represent the true elastic modulus. They characterize the relationship between stress and strain for tensile loading at strain rates greater than 100\%/s.

The stress-strain plots, for all successfully tested coupons, combined by subject and by location are shown in Figs. A1 and A2 respectively. The linear elastic material parameters for the effective or structural response of the 97 cortical bone coupons have been summarized in Table 3. Effective Young's modulus of the coupons had a weak correlation $\left(\mathrm{R}^{2}=0.51\right)$ with bone volume fraction (BVF) in the coupon gage area. Similarly, the failure stress for the coupons that broke in the gage area, had a weak correlation with $\mathrm{BVF}\left(\mathrm{R}^{2}=0.50\right.$; Fig. 8). Power law models were chosen for functional representation of these relationships (Equation 1). Failure strain had no discernable trend with BVF.

\section{$\boldsymbol{E}=18.61 \varrho^{2.22} \sigma_{f}=109.54 \varrho^{2.79} \varrho-$ Bone volume fraction $\sigma_{f}$ \\ - Effective failure stressE - Effective Young's modulus}

Equation 1 Power law relationships

The optimal value of bone phase modulus in the implicit FE models that yielded the experimentally determined effective modulus for each coupon has been summarized in Table 4. The predicted effective modulus using the average bone phase modulus of $18.51 \mathrm{GPa}$ vs. the experimentally determined modulus for each coupon is shown in Fig. 9. The coefficient of determination was improved from $51 \%$ to $54 \%$ with respect to the power law model.

The average and standard deviation of effective Young's modulus, failure stress and failure strain at the different locations is shown in the contour plots in Fig. 10. The zero standard deviation at the edges of the mapped area is an artifact of the limited number of samples at those locations. The variation of effective Young's modulus, failure stress and failure strain on the calvarium of nine individual subjects are shown in Figs. A3, A4 and A5, respectively (CT images of subject 1 did not include key anatomical landmarks and therefore its 2D projection could not be constructed). The Young's modulus of the bone phase at the osteon level as estimated from the empirical power law model and implicit FE model are shown as average and standard deviation across nine subjects in Fig. 11. These values for each individual subject are shown in Figs. A6 and A7.

One-way between subjects ANOVA showed that the mechanical properties found in this study did not vary significantly between subjects $(p>0.05)$. For investigation of variation with anatomical location, the coupons were separated into two groups depending on whether it was harvested from the parietal bone or the frontal bone. One-way within subject ANOVA tests were then run for each measurement to compare these two groups taking into account between subjects variations. The coupons were also divided into two groups, called superior and inferior, depending on whether they were harvested from the top or bottom of the calvarium (above or below $30^{\circ}$ elevation with respect to the head coordinate system). The results indicated that the effective failure stress and strain differed between the frontal and parietal bones. Interestingly, the bone phase modulus, derived using the implicit FE models, was significantly different between the superior and inferior aspects of the calvarium, but not between the frontal and parietal bones. The results of the ANOVA tests have been compiled in Table 5.

\section{Discussion}

It is known that biomaterials undergo elastic as well as plastic deformation when they are quasi-statically loaded. Consequently, their elastic modulus can only be assessed upon unloading the specimen (Luczynski et al., 2013). Plastic effects have been found to be dependent on the stress level and strain-rate. Permanent plastic deformation of bone from the human femur was found to occur at stress greater than $80 \mathrm{MPa}$ (Fondrk et al., 1988). Zioupos et al. (2008) found that plastic behavior was highly dependent on strain-rate with specimens of the human femur behaving like a brittle material at large rates. Using microscopy, they have observed much less microcracking in specimens tested at strain-rates greater than $100 \% / \mathrm{s}$, and have suggested that low strain rates allow microcracking to develop, increasing the compliance and toughness of bone. Despite the fact that the specimens in this test series were tested at strain-rates greater than $100 \% / \mathrm{s}$ and failed at an average stress of $65 \mathrm{MPa}$, it is possible that plastic deformation may have occurred within the 20 to $80 \%$ domain where elasticity was calculated. Therefore, it is possible that the numbers reported here underestimate the true elastic modulus values.

The effective mechanical properties found in this study compare well with previously published studies where cortical layer coupons from the calvarium have been tested (Evans and Lissner, 1957; Robbins and Wood, 1969; Wood, 1971; summarized in Table 3). Elastic modulus derived from ultrasound pulse transmission techniques (Peterson and Dechow, 2002) have yielded numbers that are greater than values found through tensile testing. They are even greater than cortical bone phase modulus deduced in this study and found in several others. The bending response of composite bone beam samples from calvarium was adjusted using different strategies to estimate the stiffness of the cortical layers. Hubbard (1971) used a three layer sandwich structure approach, the thicknesses of which were determined through visual inspection. Delille et al. (2007) and Auperrin et al. (2014) used the ash percentage combined with a hollow beam assumption, and Motherway et al. (2009) used micro CT to determine mid-span second moments of area. The modulus estimated in all of these studies is less compared to the current study. In addition to their treatment of curved samples from the skull as straight beams, this discrepancy in the results could be because bone from the cortical layers and the porous diploe have been treated identically.

The effective Young's modulus of the cortical coupons is compared to those published by other authors for dynamic coupon tensile tests of cortical bone from the human body in Table 6. A gradually increasing modulus and failure stress is observed as we travel lower in the body. The variance in both parameters is seen to decline. This observation is consistent with Turner's proposal (Turner, 1992) that stress exerted on bone may influence its remodeling and architecture.

The fact that modeling the full micro-structure of cortical bone from the skull does not result in a large advantage in terms of predictive ability, as compared to using just porosity, reinforces Dempster's

Table 6

Effective mechanical properties from this study compared to other coupon studies of human cortical bone.

\begin{tabular}{|c|c|c|c|c|}
\hline & Source & $\begin{array}{l}\text { Strain rate } \\
{\left[\mathrm{s}^{-1}\right]}\end{array}$ & $\begin{array}{l}\text { Modulus } \\
{[\mathrm{GPa}]}\end{array}$ & $\begin{array}{l}\text { Failure stress } \\
{[\mathrm{MPa}]}\end{array}$ \\
\hline Current study & Calvarium & 1.1 & $12.0 \pm 3.3$ & $65.0 \pm 21.1$ \\
\hline $\begin{array}{l}\text { (Kemper et al., } \\
\text { 2005) }\end{array}$ & Rib & 0.5 & $13.9 \pm 3.7$ & $124.3 \pm 35.4$ \\
\hline $\begin{array}{l}\text { (Subit et al., } \\
\text { 2011) }\end{array}$ & Rib & 1.7 & $13.5 \pm 2.6$ & $112.1 \pm 24.5$ \\
\hline $\begin{array}{l}\text { (Hansen et al., } \\
\text { 2008) }\end{array}$ & Femur & 1.0 & 16.5 & 120.0 \\
\hline $\begin{array}{l}\text { (Subit et al., } \\
\text { 2013) }\end{array}$ & Femur & 1.0 & $19.8 \pm 2.2$ & $123.7 \pm 25.1$ \\
\hline $\begin{array}{c}\text { (Subit et al., } \\
\text { 2013) }\end{array}$ & Tibia & 1.0 & $22.7 \pm 0.9$ & $167.4 \pm 13.2$ \\
\hline
\end{tabular}


(1967) finding that the osteonal grain in this region is randomly oriented. It means that at a length scale larger than the coupon gage area $(>2.5 \mathrm{~mm})$, modeling the skull cortical layers using an isotropic material is adequate.

The bone phase modulus deduced through BVF based power law model and through implicit FE models compares well with nano-indentation studies done by Rho et al. (1997) and Zysset et al. (1999) on cortical bone from tibia and femur (Table 4). Tensile tests conducted on single osteons from the human femoral shaft (Ascenzi and Bonucci, 1967) show that these values of bone phase modulus are closer to that of dry osteons. However, it should be noted that interstitial lamellae is stiffer than the osteons (Rho et al., 1997; Zysset et al., 1999). The variance in the data from this study is comparable to the nano-indentation studies and is less than the variance in Ascenzi and Bonucci's (1967) data.

The difference in the bone phase modulus, as calculated from micro $\mathrm{FE}$, between the superior and inferior aspects of the calvarium may be caused by the in-vivo loading conditions of the skull. Due to gravity, the skull generally endures more load in the inferior aspect as compared to the superior. This may be the reason the cortical bone in the inferior aspect is stiffer than that in the superior aspect (19.4 vs. $17.5 \mathrm{GPa}$ respectively).

Despite the difficulties of sample preparation, tensile mode of testing was chosen because of the shape of the outer cortical layer of the calvarium. Testing under compression at a high strain rate is difficult because of the thinness of the cortical layers. Nanoindentation requires dehydration, embedding, and polishing of the samples which may significantly change the in-vivo mechanical characteristics of bone. As pointed out by Rho et al. (1993), the modulus measured using ultrasound is greater by more than $10 \%$ compared to estimates using tensile tests.

\section{Conclusions}

1. Effective mechanical properties including failure characteristics of outer cortical layer of the adult human calvarium under tension in the tangential direction were reported (Table 3 ).

2. Bone phase modulus was calculated using both empirical correlation between effective modulus and BVF, and micro FE models of coupons (Table 4).

3. Small improvement in predictability from micro FE models compared to the BVF based power law model may indicate lack of consistent directionality in osteonal grain pattern.

4. Significant differences were found between frontal and parietal bone for effective failure stress and failure strain, and superior and inferior aspect of calvarium for bone phase modulus derived using micro FE models.

5. Effective modulus and failure properties, and bone phase modulus did not vary significantly between subjects.

\section{Acknowledgement}

This research was sponsored by contract no. N00421-11-C-0004 from the U.S. Naval Air Warfare Center, Aircraft Division, Patuxent River, MD.

\section{Appendix A}

See Figs. A1-A7. 


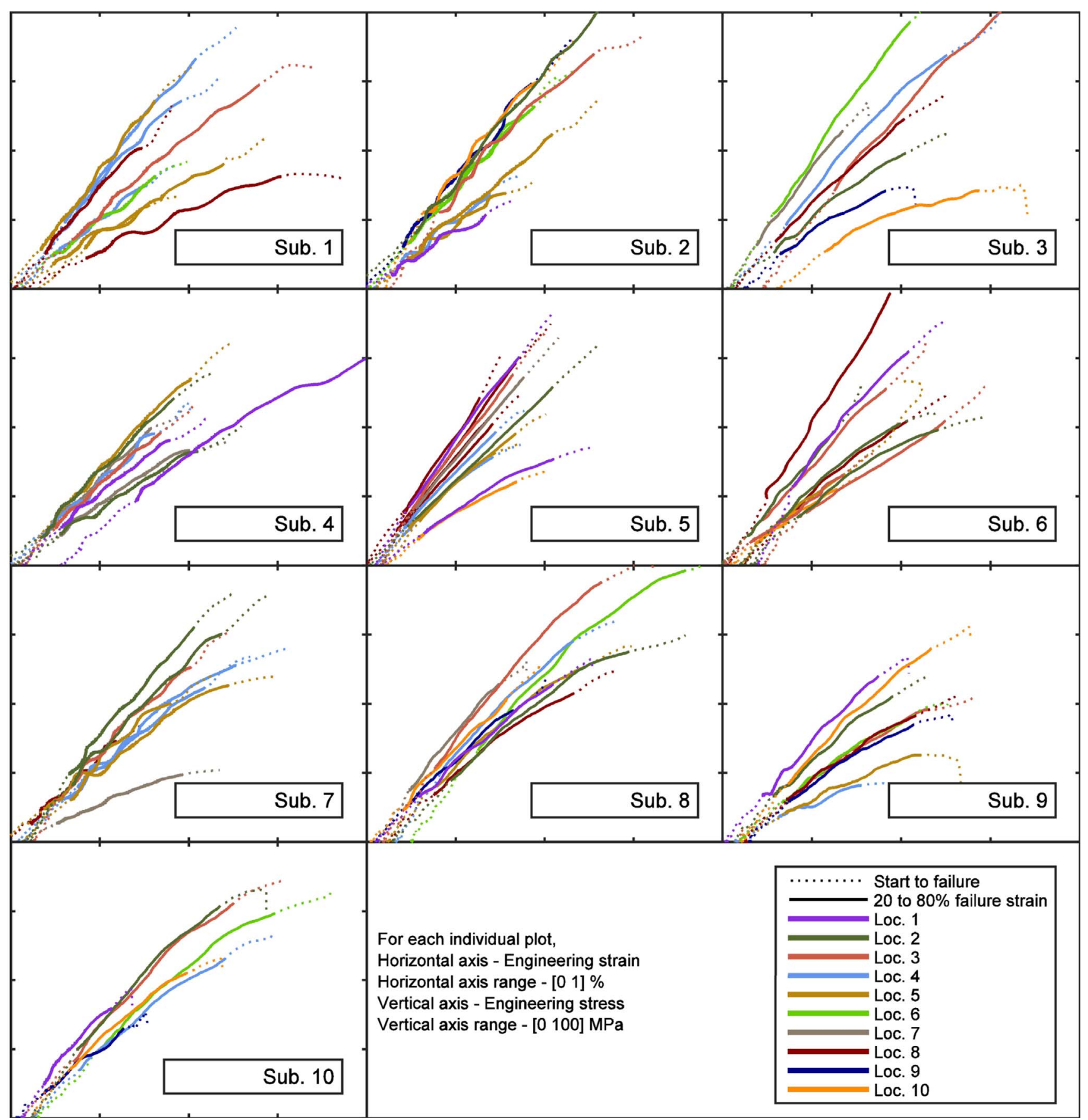

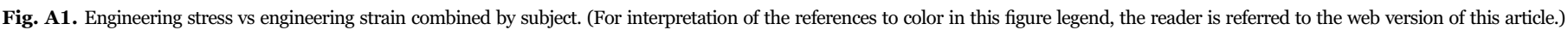




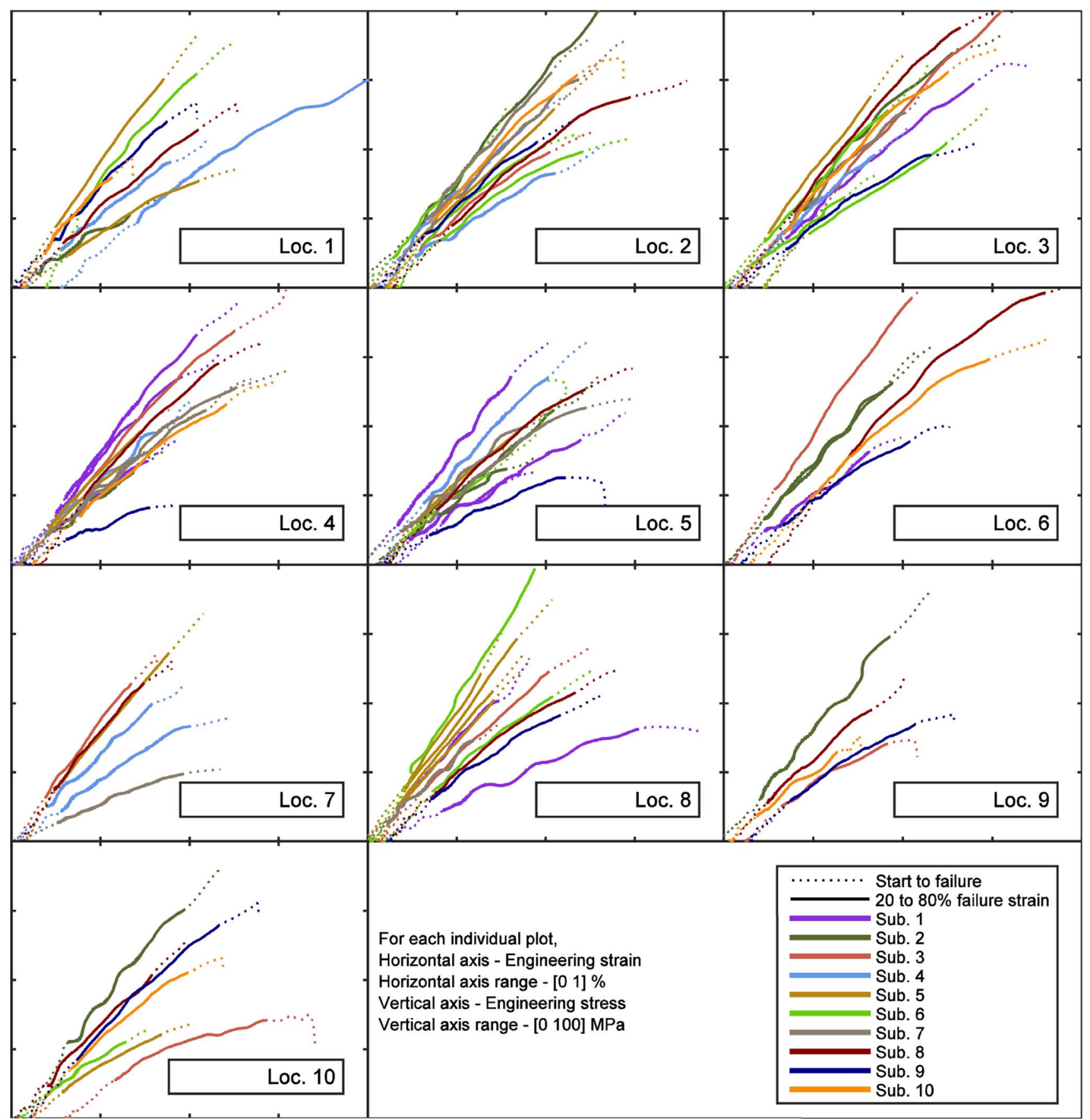

Fig. A2. Engineering stress vs engineering strain combined by location. (For interpretation of the references to color in this figure legend, the reader is referred to the web version of this article.) 


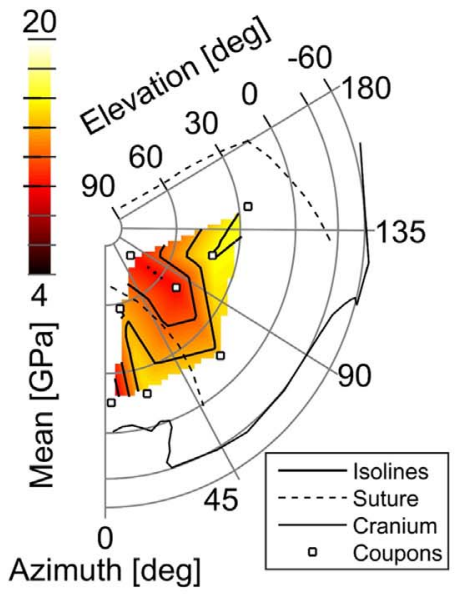

Subject 2

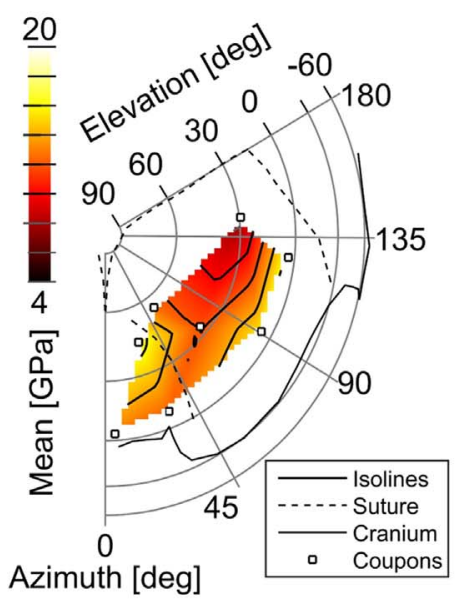

Subject 5

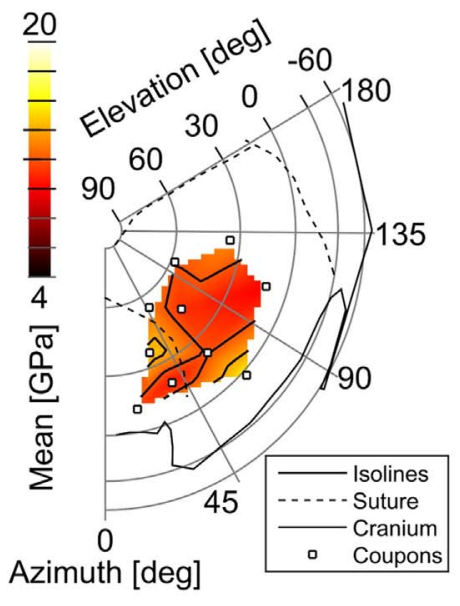

Subject 8

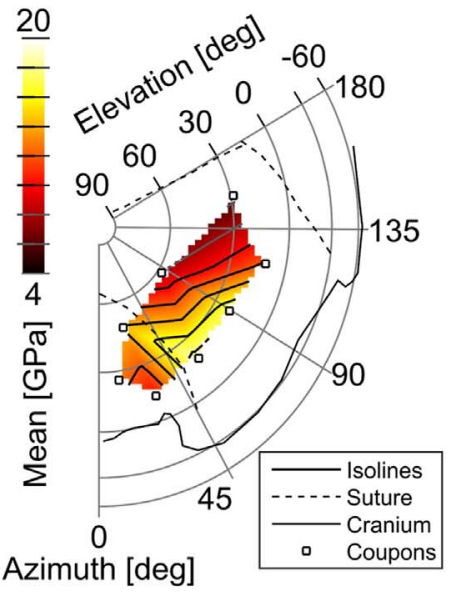

Subject 3

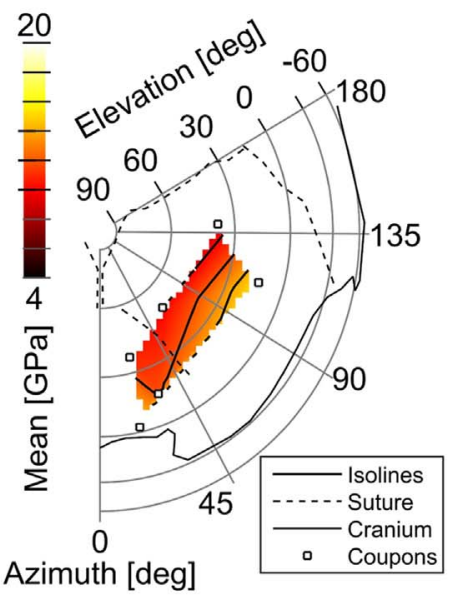

Subject 6

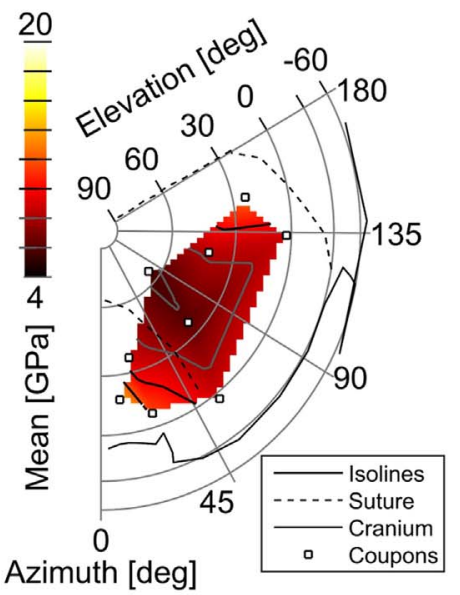

Subject 9

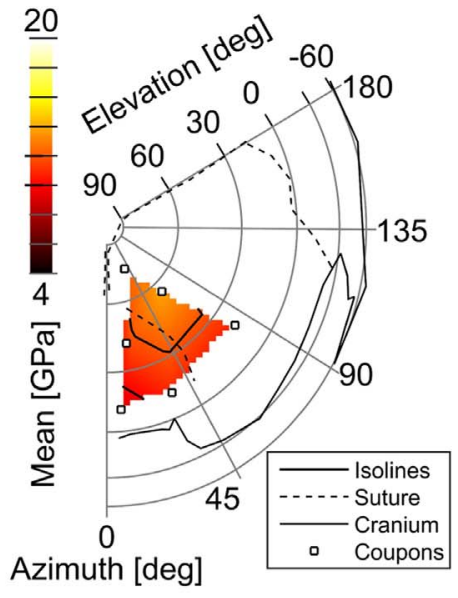

Subject 4

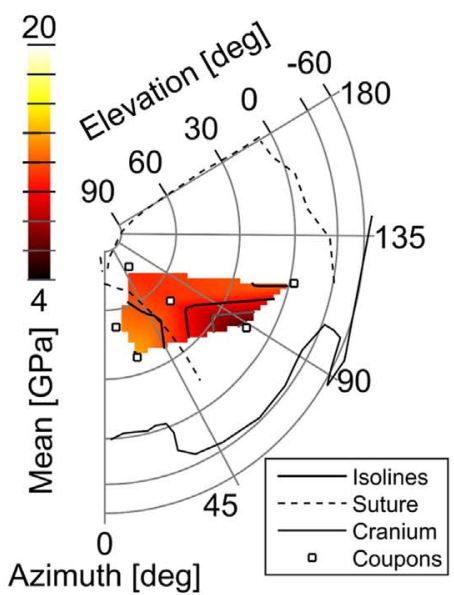

Subject 7

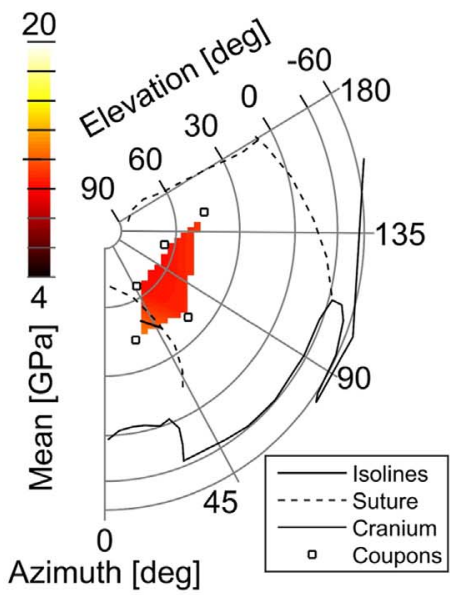

Subject 10

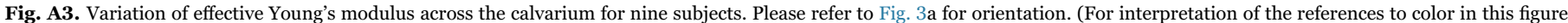
legend, the reader is referred to the web version of this article.) 


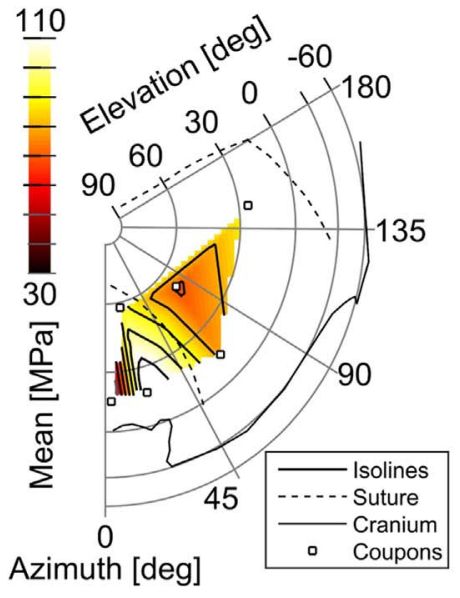

Subject 2

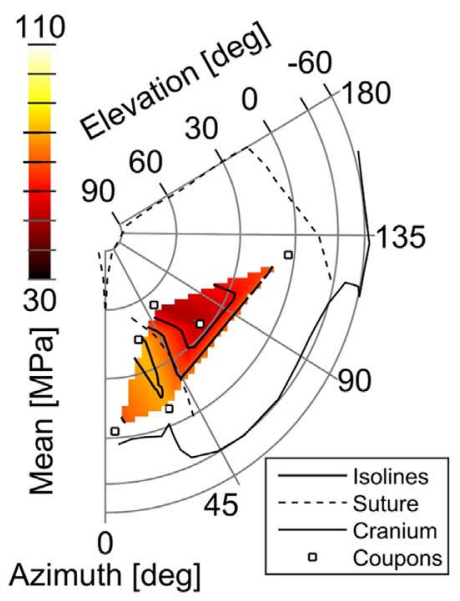

Subject 5

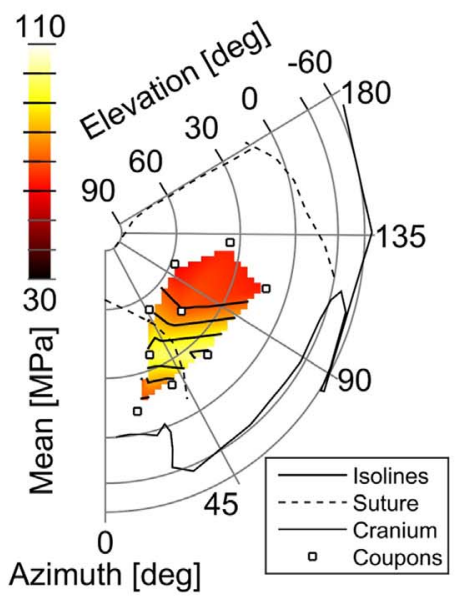

Subject 8

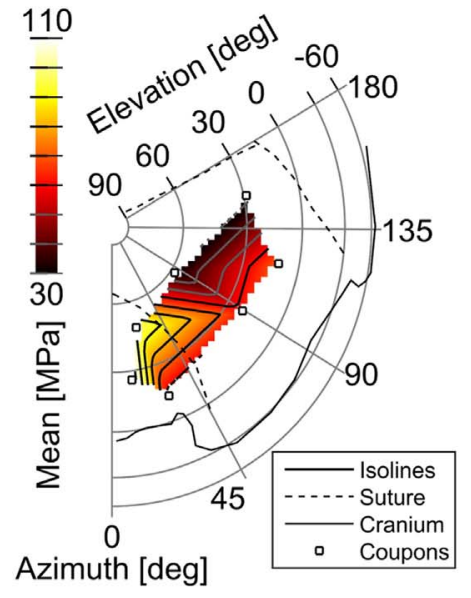

Subject 3

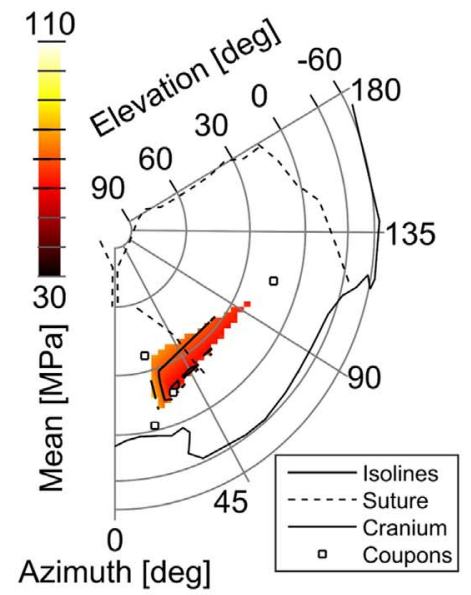

Subject 6

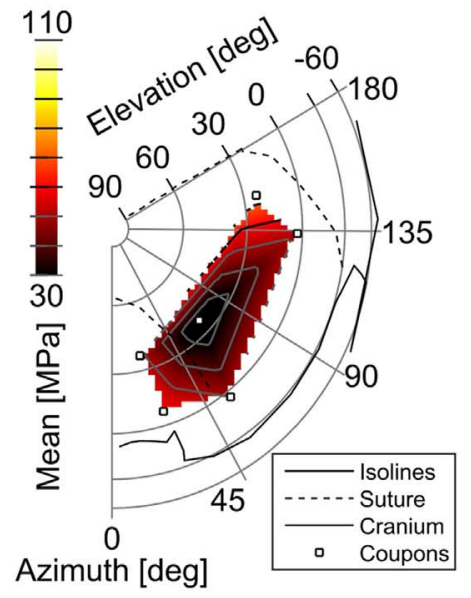

Subject 9

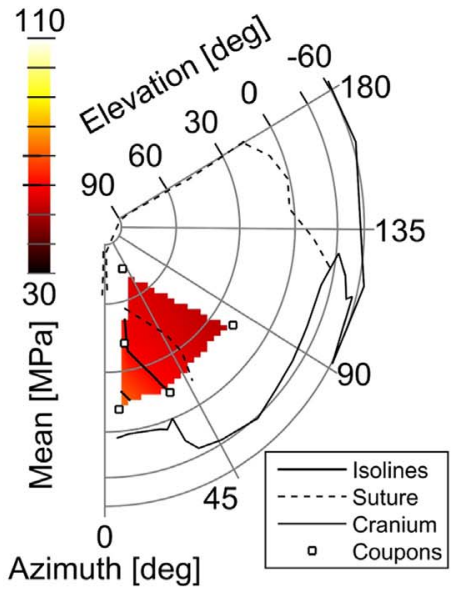

Subject 4

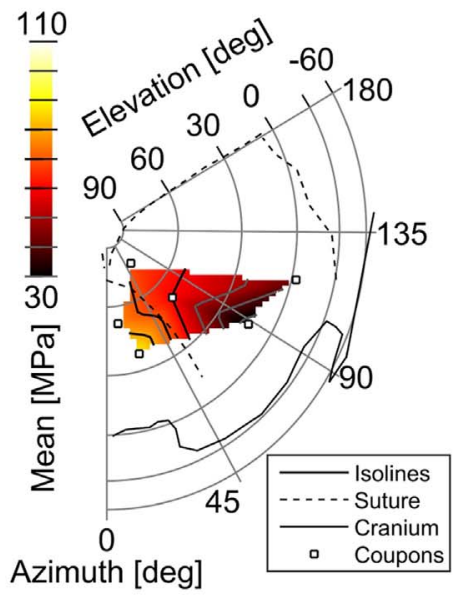

Subject 7

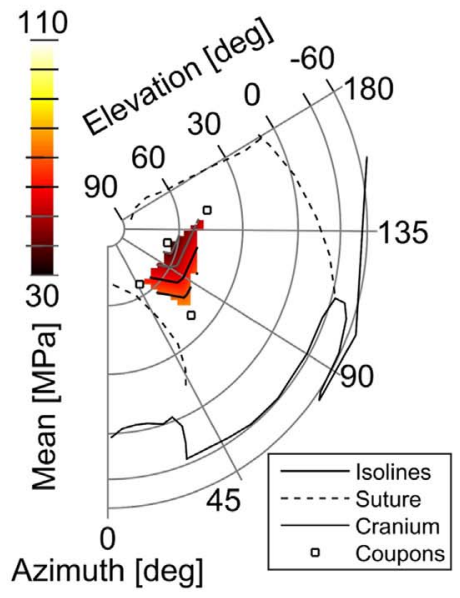

Subject 10

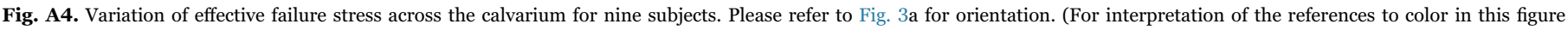
legend, the reader is referred to the web version of this article.) 


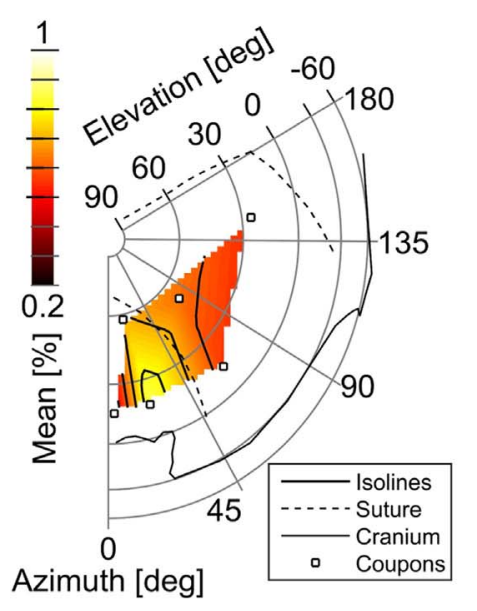

Subject 2

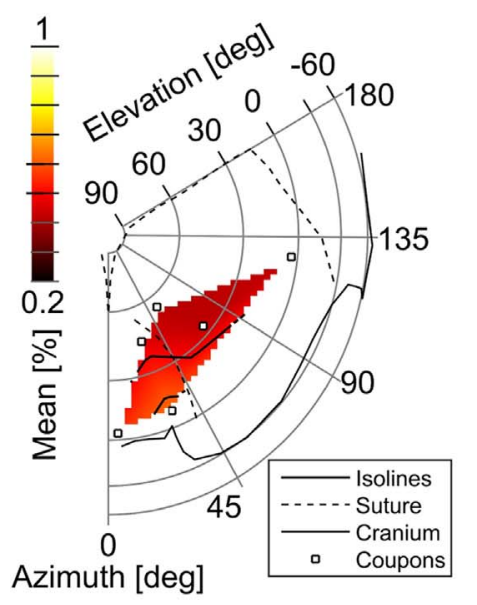

Subject 5

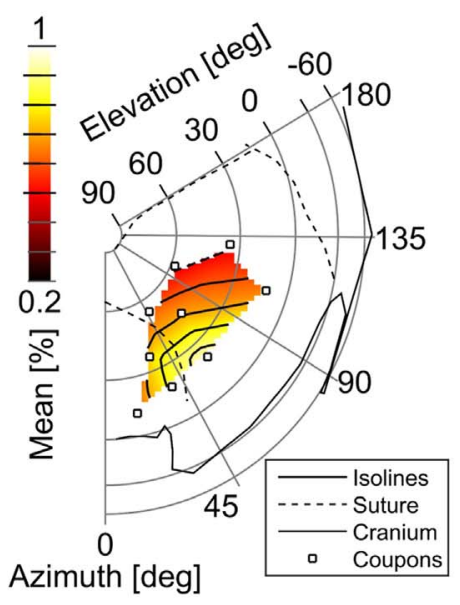

Subject 8

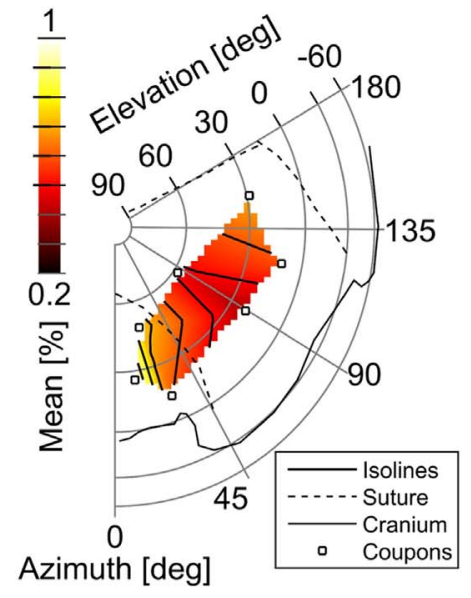

Subject 3

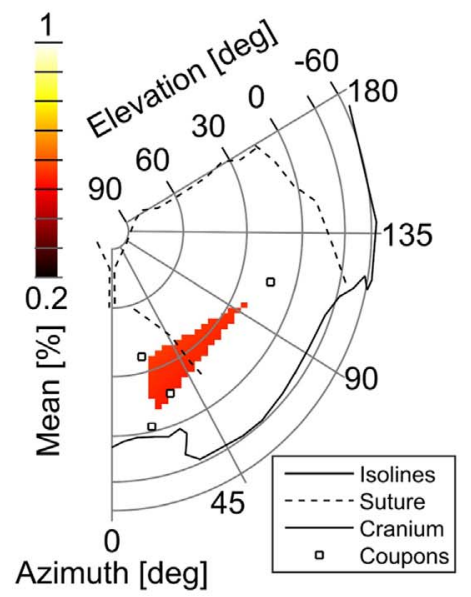

Subject 6

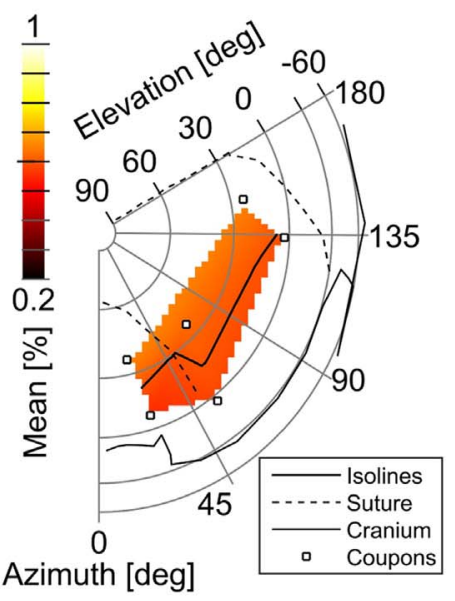

Subject 9

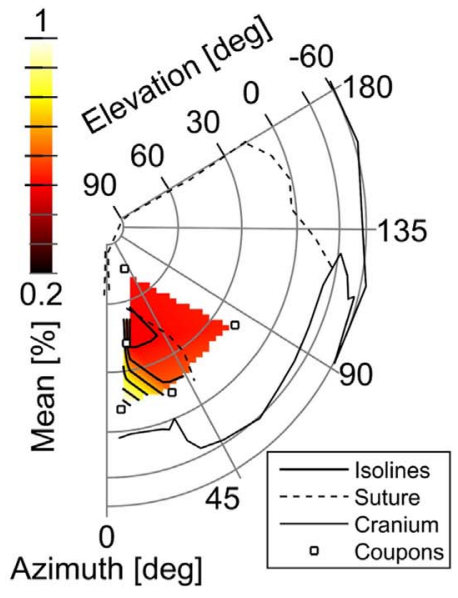

Subject 4

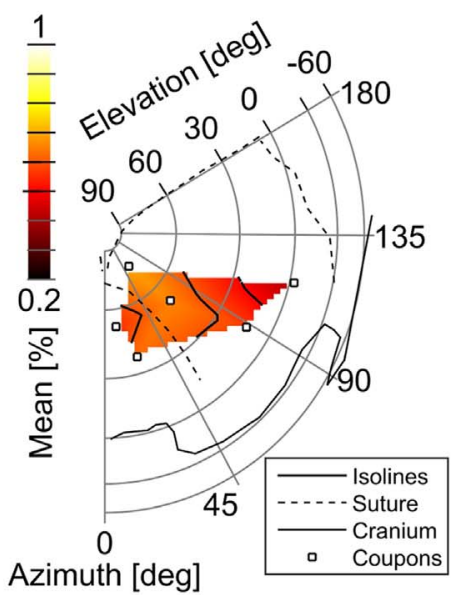

Subject 7

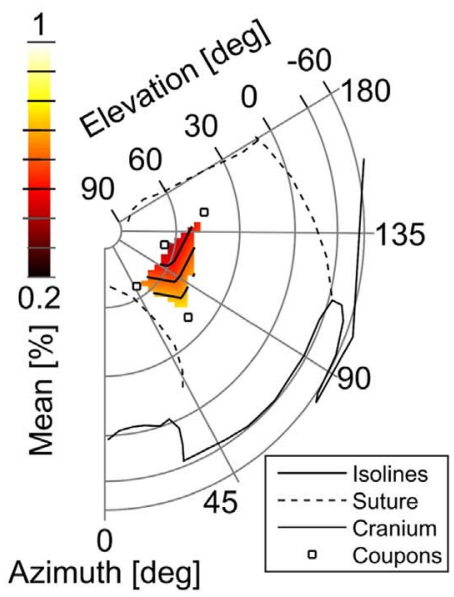

Subject 10

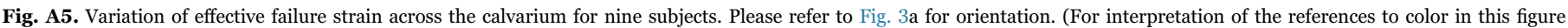
legend, the reader is referred to the web version of this article.) 


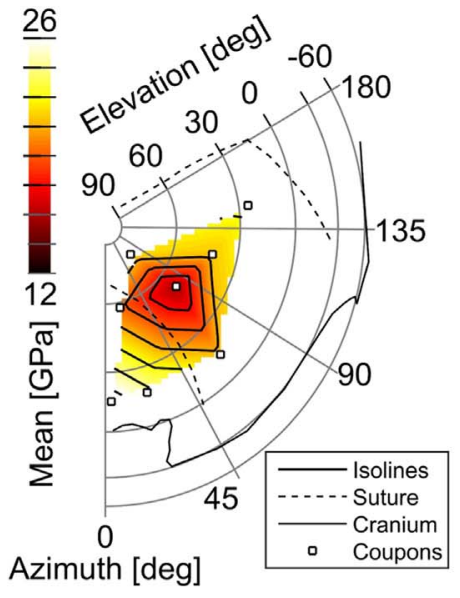

Subject 2

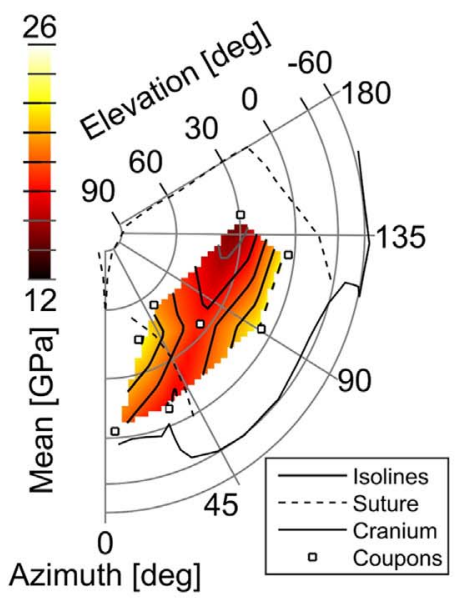

Subject 5

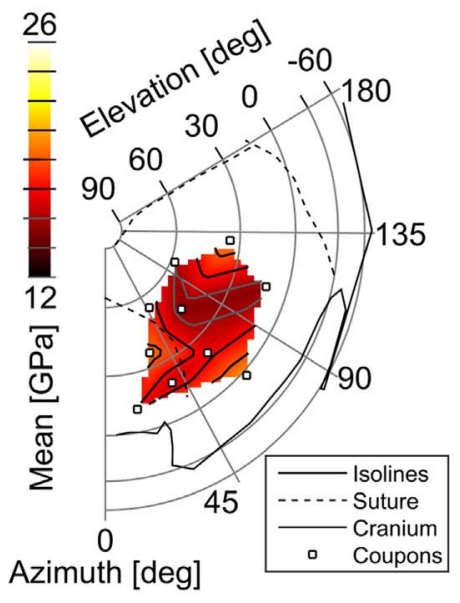

Subject 8

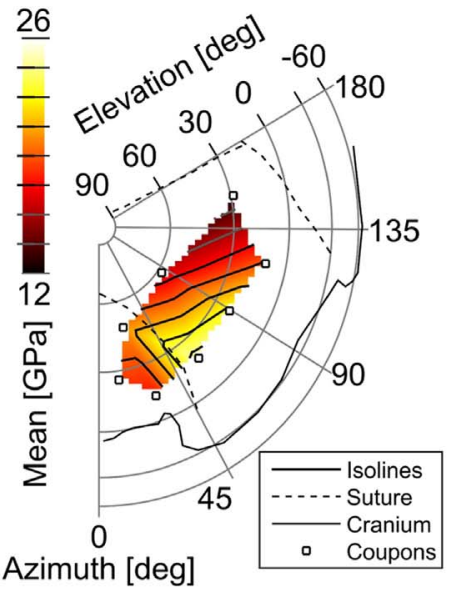

Subject 3

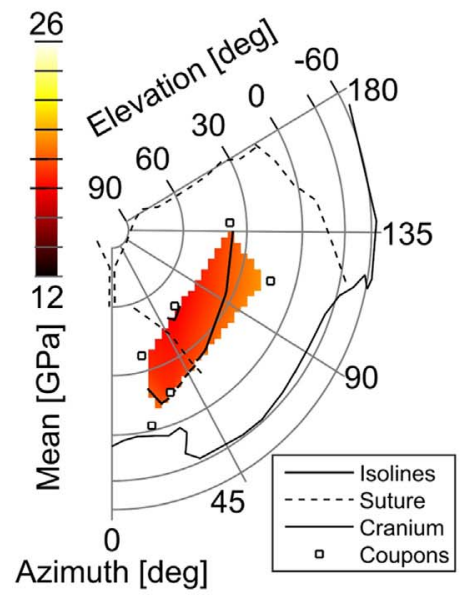

Subject 6

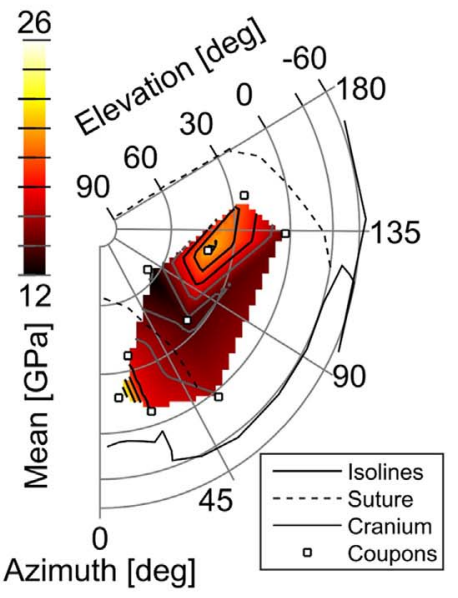

Subject 9

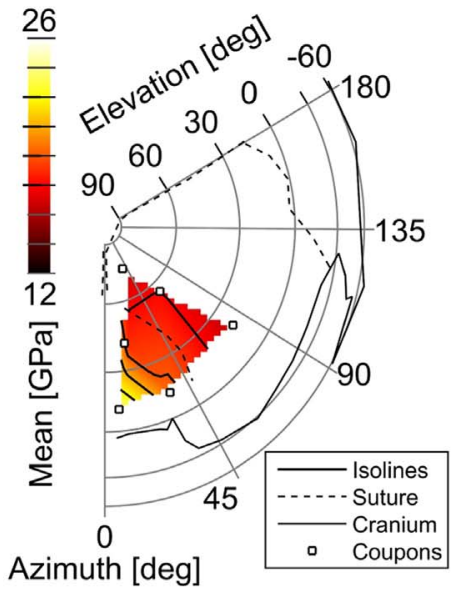

Subject 4

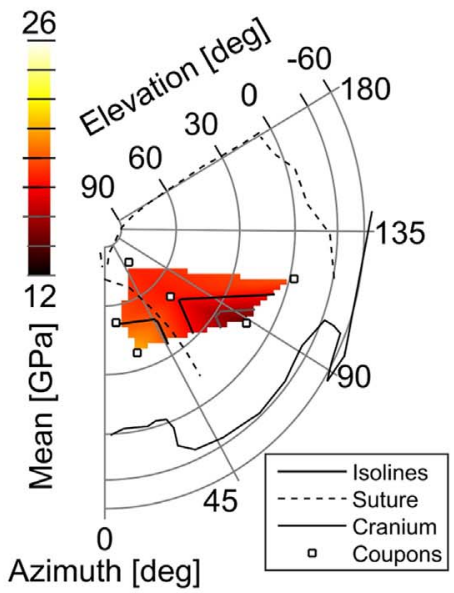

Subject 7

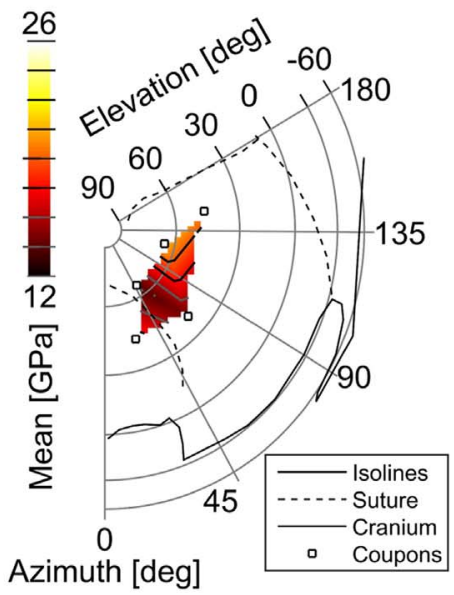

Subject 10

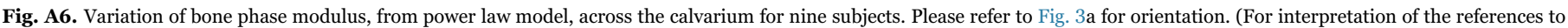
color in this figure legend, the reader is referred to the web version of this article.) 


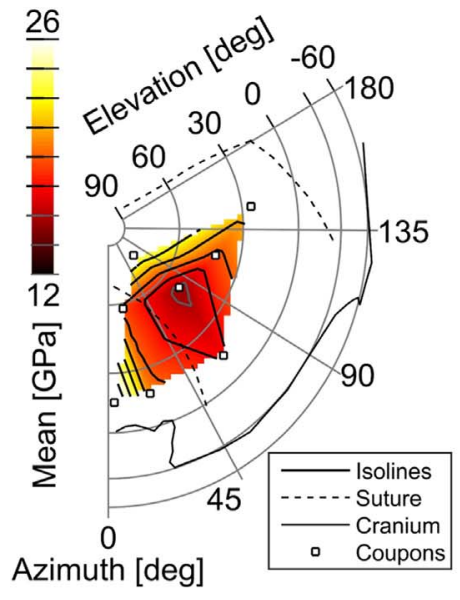

Subject 2

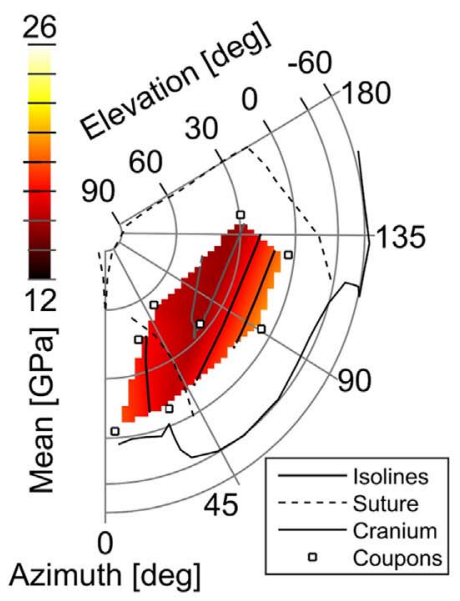

Subject 5

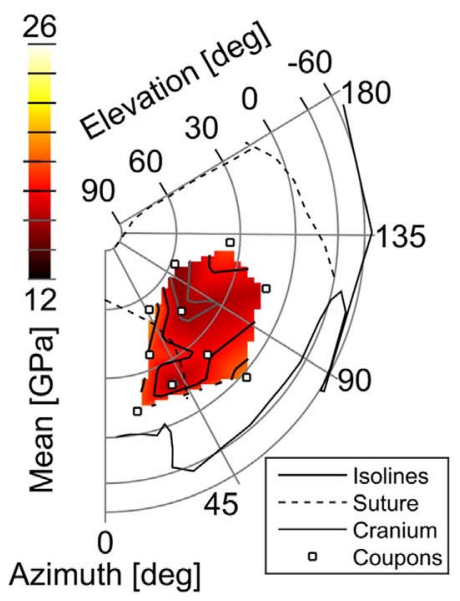

Subject 8

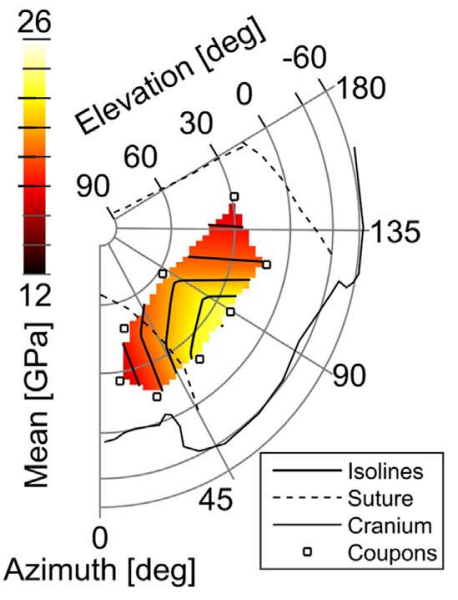

Subject 3

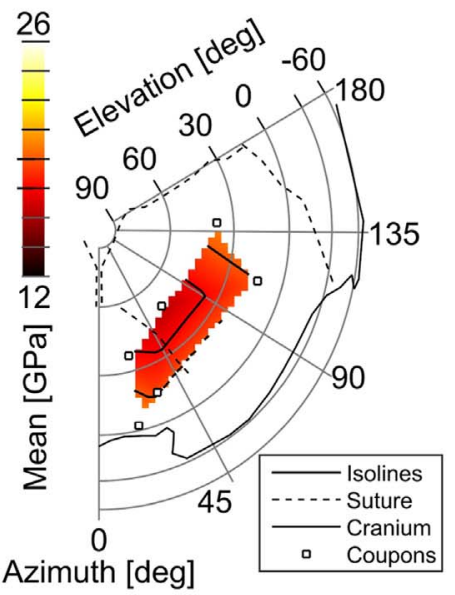

Subject 6

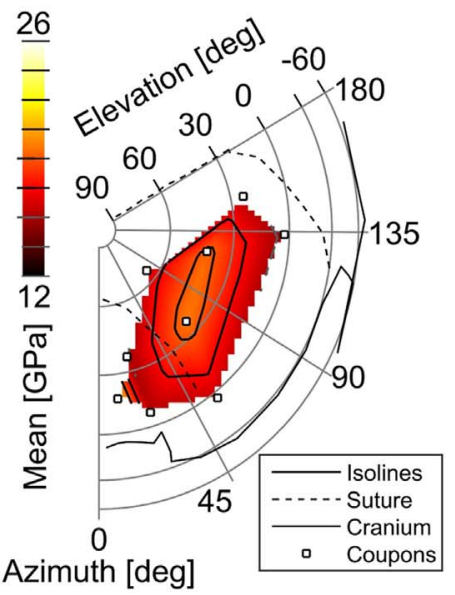

Subject 9

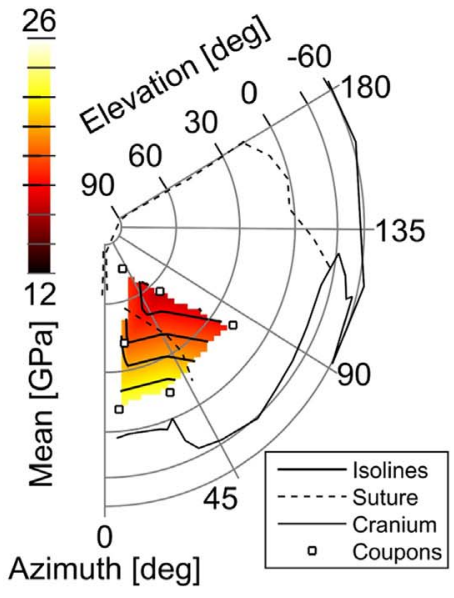

Subject 4

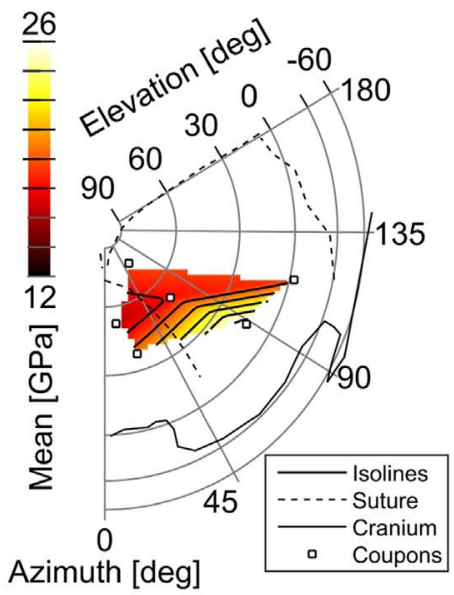

Subject 7

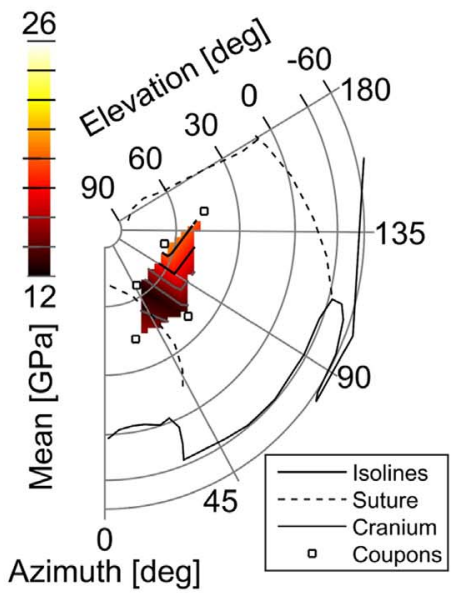

Subject 10

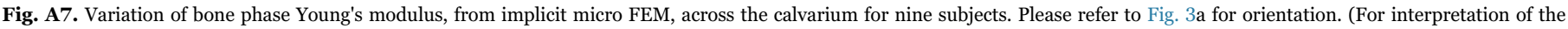
references to color in this figure legend, the reader is referred to the web version of this article.)

\section{References}

Ascenzi, A., Bonucci, E., 1967. The tensile properties of single osteons. Anat. Rec. 158, 375-386. http://dx.doi.org/10.1002/ar.1091580403.

Asgharpour, Z., Baumgartner, D., Willinger, R., Graw, M., Peldschus, S., 2014. The validation and application of a finite element human head model for frontal skull fracture analysis. J. Mech. Behav. Biomed. Mater. 33, 16-23. http://dx.doi.org/ 10.1016/j.jmbbm.2013.02.010.

Auperrin, A., Delille, R., Lesueur, D., Bruyère, K., Masson, C., Drazétic, P., 2014. Geometrical and material parameters to assess the macroscopic mechanical behaviour of fresh cranial bone samples. J. Biomech. 47, 1180-1185. http:// dx.doi.org/10.1016/j.jbiomech.2013.10.060.

Boruah, S., Henderson, K., Subit, D.L., Salzar, R.S., Shender, B.S., Paskoff, G.R., 2013. Response of human skull bone to dynamic compressive loading. In: Proceedings of IRCOBI Conference 
Boruah, S., Paskoff, G.R., Shender, B.S., Subit, D.L., Salzar, R.S., Crandall, J.R., 2015 Variation of bone layer thicknesses and trabecular volume fraction in the adult male human calvarium. Bone 77, 120-134. http://dx.doi.org/10.1016/ j.bone.2015.04.031.

Delille, R., Lesueur, D., Potier, P., Drazetic, P., Markiewicz, E., 2007. Experimental study of the bone behaviour of the human skull bone for the development of a physical head model. Int. J. Crashworth. 12, 101-108. http://dx.doi.org/10.1080/ 13588260701433081.

Dempster, W.T., 1967. Correlation of types of cortical grain structure with architectural features of the human skull. Am. J. Anat. 120, 7-31. http://dx.doi.org/10.1002/ aja.1001200103.

Dong, X.N., Guo, X.E., 2004. The dependence of transversely isotropic elasticity of human femoral cortical bone on porosity. J. Biomech. 37, 1281-1287. http:// dx.doi.org/10.1016/j.jbiomech.2003.12.011.

Evans, F.G., Lissner, H.R., 1957. Tensile and compressive strength of human parietal bone. J. Appl. Physiol. 10, 493-497.

Fischer, H., 2010. US Military Casualty Statistics: Operation New Dawn, Operation Iraqi Freedom, and Operation Enduring Freedom.

Fondrk, M., Bahniuk, E., Davy, D.T., Michaels, C., 1988. Some viscoplastic characteristics of bovine and human cortical bone. J. Biomech. 21, 623-630. http://dx.doi.org/ 10.1016/0021-9290(88)90200-X.

Got, C., Patel, A., Fayon, A., Tarriere, C., Walfisch, G., 1978. Results of experimental head impacts on cadavers: the various data obtained and their relations to some measured physical parameters. In: Proceedings of Stapp Car Crash Conference. pp. 57-99.

Hansen, U., Zioupos, P., Simpson, R., Currey, J.D., Hynd, D., 2008. The effect of strain rate on the mechanical properties of human cortical bone. J. Biomech. Eng. 130, 11011.

Hodgson, V.R., Brinn, J., Thomas, L.M., Greenberg, S.W., 1970. Fracture Behavior of the Skull Frontal Bone Against Cylindrical Surfaces

Horgan, T.J., Gilchrist, M.D., 2003. The creation of three-dimensional finite element models for simulating head impact biomechanics. Int. J. Crashworth. 8, 353-366.

Hubbard, R.P., 1971. Flexure of layered cranial bone. J. Biomech. 4, 251-263.

Kemper, A.R., McNally, C., Kennedy, E.A., Manoogian, S.J., et al., 2005. Material properties of human rib cortical bone from dynamic tension coupon testing. Stapp Car Crash J. 49, 199-230.

Luczynski, K.W., Brynk, T., Ostrowska, B., Swieszkowski, W., Reihsner, R., Hellmich, C., 2013. Consistent quasistatic and acoustic elasticity determination of poly-L-lactidebased rapid-prototyped tissue engineering scaffolds. J. Biomed. Mater. Res. A 101, 138-144. http://dx.doi.org/10.1002/jbm.a.34316.

McCalden, R.W., McGeough, J.A., Barker, M.B., Court-Brown, C.M., 1993. Age-related changes in the tensile properties of cortical bone. The relative importance of changes in porosity, mineralization, and microstructure. J. Bone Jt. Surg. 75, 1193-1205.

Moss, W.C., King, M.J., Blackman, E.G., 2009. Skull flexure from blast waves: a mechanism for brain injury with implications for helmet design. Phys. Rev. Lett. 103, 108702.

Motherway, J.A., Verschueren, P., Van der Perre, G., Vander Sloten, J., Gilchrist, M.D., 2009. The mechanical properties of cranial bone: the effect of loading rate and cranial sampling position. J. Biomech. 42, 2129-2135. http://dx.doi.org/10.1016/ j.jbiomech.2009.05.030.
Nahum, A.M., Gatts, J.D., Gadd, C.W., Danforth, J., 1968. Impact Tolerance of the Skull and Face.

Panzer, M.B., Myers, B.S., Capehart, B.P., Bass, C.R., 2012. Development of a finite element model for blast brain injury and the effects of CSF cavitation. Ann. Biomed. Eng. 40, 1530-1544. http://dx.doi.org/10.1007/s10439-012-0519-2.

Peterson, J., Dechow, P.C., 2002. Material properties of the inner and outer cortical tables of the human parietal bone. Anat. Rec. 268, 7-15. http://dx.doi.org/10.1002/ ar.10131.

Rahmoun, J., Auperrin, A., Delille, R., Naceur, H., Drazetic, P., 2014. Characterization and micromechanical modeling of the human cranial bone elastic properties. Mech. Res. Commun. 60, 7-14. http://dx.doi.org/10.1016/j.mechrescom.2014.04.001.

Rho, J.Y., Ashman, R.B., Turner, C.H., 1993. Young's modulus of trabecular and cortical bone material: ultrasonic and microtensile measurements. J. Biomech. 26, 111-119. http://dx.doi.org/10.1016/0021-9290(93)90042-D.

Rho, J.-Y., Tsui, T.Y., Pharr, G.M., 1997. Elastic properties of human cortical and trabecular lamellar bone measured by nanoindentation. Biomaterials 18, 1325-1330 . http://dx.doi.org/10.1016/S0142-9612(97)00073-2.

Robbins, D.H., Wood, J.L., 1969. Determination of mechanical properties of the bones of the skull. Exp. Mech. 9, 236-240.

Snell, F.I., Halter, M.J., 2010. A signature wound of war: mild traumatic brain injury. J. Psychosoc. Nurs. Ment. Health Serv. 48, 22-28.

Subit, D., ARREGUI-DALMASES, C., SALAZAR, R., Crandall, J., 2013. Pediatric, adult and elderly bone material properties. In: Proceedings of the 2013 IRCOBI Conference. Paper IRC-13-87.

Subit, D., de Dios, E. del, P., Valazquez-Ameijide, J., Arregui-Dalmases, C., Crandall, J., 2011. Tensile Material Properties of Human rib Cortical Bone Under Quasi-static and Dynamic Failure Loading and Influence of the Bone Microstucture on Failure Characteristics. arXiv Prepr. arXiv1108.0390.

Torimitsu, S., Nishida, Y., Takano, T., Koizumi, Y., Hayakawa, M., Yajima, D., Inokuchi, G., Makino, Y., Motomura, A., Chiba, F., Iwase, H., 2014. Effects of the freezing and thawing process on biomechanical properties of the human skull. Leg. Med. 16, 102-105. http://dx.doi.org/10.1016/j.legalmed.2013.11.005.

Turner, C.H., 1992. On Wolff's law of trabecular architecture. J. Biomech. 25, 1-9. http://dx.doi.org/10.1016/0021-9290(92)90240-2.

Wang, X., Shen, X., Li, X., Agrawal, C.M., 2002. Age-related changes in the collagen network and toughness of bone. Bone 31, 1-7. http://dx.doi.org/10.1016/S87563282(01)00697-4.

Wood, J.L., 1971. Dynamic response of human cranial bone. J. Biomech. 4, 1-12. http:// dx.doi.org/10.1016/0021-9290(71)90010-8.

Zioupos, P., Currey, J., 1998. Changes in the stiffness, strength, and toughness of human cortical bone with age. Bone 22, 57-66. http://dx.doi.org/10.1016/S8756-3282(97) 00228-7.

Zioupos, P., Hansen, U., Currey, J.D., 2008. Microcracking damage and the fracture process in relation to strain rate in human cortical bone tensile failure. J. Biomech. 41, 2932-2939. http://dx.doi.org/10.1016/j.jbiomech.2008.07.025.

Zysset, P.K., Edward Guo, X., Edward Hoffler, C., Moore, K.E., Goldstein, S.A., 1999. Elastic modulus and hardness of cortical and trabecular bone lamellae measured by nanoindentation in the human femur. J. Biomech. 32, 1005-1012. http:// dx.doi.org/10.1016/S0021-9290(99)00111-6. 